\title{
NOVEL CONCEPTS IN WELD METAL SCIENCE: ROLE OF GRADIENTS AND COMPOSITE STRUCTURE
}

\author{
Progress Report
}

For the Period January 1, 1991 - December 31, 1991

D.K. Matlock and D.L. Olson

Colorado School of Mines

Center for Welding and Joining Research

Golden, Colorado 80401

November 1991

Prepared for

THE U.S. DEPARTMENT OF ENERGY

AGREEMIENT NO. DE-FG02-87ER45308

Center for Welding and

JoInING RESEARCH

Colorado School of Mines

Golden, Colorado 80401 
DOE/ER/ $45308--5$

DE92 005082

NOVEL CONCEPTS IN WELD METAL SCIENCE:

ROLE OF GRADIENTS AND COMPOSITE STROCTURE

Annual Technical Report

January 1, 1991 to December 31, 1991

Submitted to:

United States Department of Energy

Division of Basic Energy Sciences

Metallurgy and Materials Branch

Submitted by:

D.R. Matlock and D.L. Olson

Center for Welding and Joining Research Colorado School of Mines

Golden, Colorado 80401

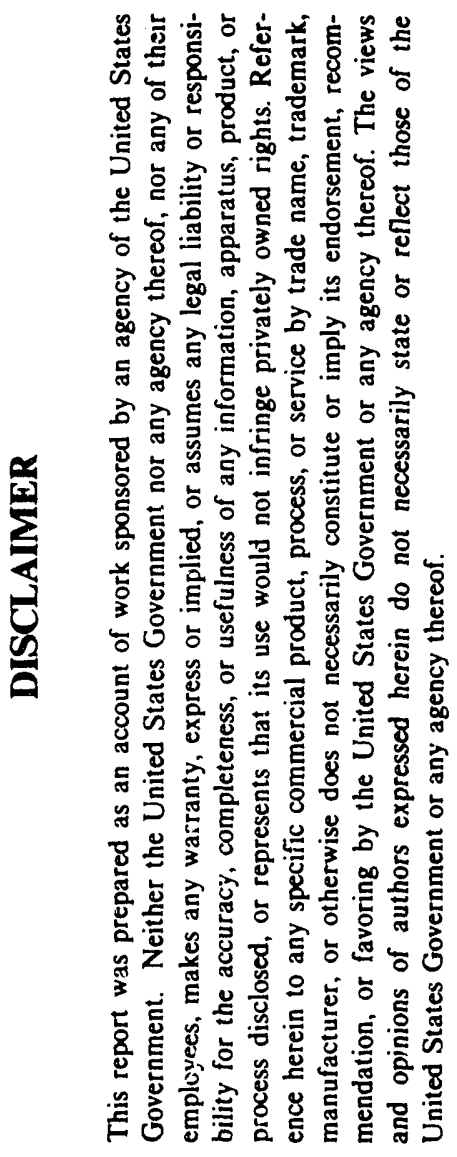

December, 1991

The United Siates Department of Energy

Agreement No. DE-FG02-87ER45308 
TABIE OF CONTENTS

Page

Abstract. . . . . . . . . . . . . . . . . . . . . . . . . 1

1.0 Introduction. . . . . . . . . . . . . . . . . . . . . 2

2.0 Review of Work Completed on Phase Transformations in

Cored Structure. . . . . . . . . . . . . . . . . . . . 5

2.1 Oxide Inclusion Formation in Cored Structure. . . . . . . . 5

2.2 Martensite Formation in Cored High Alloy Steels . . . . . . 8

2.3 TCP Phase Formation in Cored High Nickel Alloys . . . . . . 13

2.4 Role of Compositional Gradients............. . 16

3.0 Work in Progress. . . . . . . . . . . . . . . . . . . . . . 19

3.1 Cracking Behavior of Cored Structures . . . . . . . . . . . 19

3.1.1 Brittle Fracture . . . . . . . . . . . . . . . . 21

3.1.2 Ductile Fracture . . . . . . . . . . . . . . . . . . 24

3.2 The Effects of Dynamic Compositional Gradients on the

Creep Behavior of Veld Metal. . . . . . . . . . . . . . . . 29

3.3 Particulate Metal Matrix Composite as a Weld Deposit. . . . 36

3.3.1 Solidification and Fluid Flow Considerations . . . . 38

3.3.2 Experimental Design and Procedures.......... . 39

3.3.3 Results and Discussion . . . . . . . . . . . . . . . 44

3.3.4 Movement of the Particle in the Liquid Weld Metal. 53

3.3.5 Average Size and Area Fractions of Second Phase

In the Weld Deposit. . . . . . . . . . . . . . . . . 57

3.3.6 Conceptional Design Criteria of the Composite

Weld Deposits with Desired Properties. . . . . . . . 61

3.3.7 Summary: Metal Matrix Composite Weld Deposits... 61

4.0 References. . . . . . . . . . . . . . . . . . . 64

5.0 Collaborative Work. . . . . . . . . . . . . . . . . . 68

6.0 Accomplishments During This Contract Year............ . 69

6.1 Summary of Accomplishments. . . . . . . . . . . . . . . . 69

6.2 Publications: Accepted and Published........... 70

6.3 Manuscripts: Submitted and in Preparation. . . . . . . . . 71

6.4 Awards. . . . . . . . . . . . . . . . . . . . 71

7.0 Anticipated Results During the Next Contract Period......... 72

7.1 Current and Future Work . . . . . . . . . . . . . . . . . 72

8.0 Research Personnel. . . . . . . . . . . . . . . . . . . 73 


\section{ABSTRACT}

The effects of compositional and microstructural gradients on weld metal properties are being investigated. Crack propagation in solidified alloy structures is being characterized as to solidification orlentation and the profile of the compositional variations. The effects of compositional gradients, are considered based on a thermodynamic analysis, referred to as the Cahn-H1liard analysis, which describes the degree to which a local surface energy is modified by the presence of a compositional gradient. The analysis predicts that both ductile and brittle fracture mechanisms are enhanced by the presence of a composition gradient.

Special techniques to produce laboratory samples with microstructures which simulate the composition and microstructure gradients in solidified weld metal are used, along with appropriate mathematical models, to evaluate the properties of the composite weld metals. The composite modeling techniques are being applied to describe the effects of compositional and microstructural gradients on weld metal properties in N1-Cu alloys.

The development of metal matrix composite weld deposits on austenitic stainless steels has been studied. The particulate metal matrix composites were produced with ceramic or refractory metal powder filled cored wire, which was gas tungsten arc and gas metal arc welded. With specific particle size distributions and material density, it is possible to produce particulate metal matrix weld deposits with uniform spatial particle distributions. 


\subsection{INTRODUCTION}

Weldments represent complex heterogeneous materials which contain gradients in microstructure, composition, and properties. Consequently the compositional gradient itself, or the microstructural gradients transformed from the compositional gradients, can significantly affect the weld metal mechanical behavior.

The Colorado School of Mines has three efforts contributing to Its program on the behavior of materials with significant compositional and microstructural gradients. These research efforts are on: (1.) the nature of crack propagation through as solidified material, (2) the modeling of local creep behavior with dynamic concentration gradients, and (3) mechanical behavior of metal matrix composite weld deposits in high temperature service. The program involves experimental, analytical and modeling efforts.

The unique feature which is in all parts of this research program is the existance of a cored structure. On cooling through the two phase (11quidsolid) fleld, a compositional profile in the liquid ahead of the solid/liquid interface develops. The profile is controlled by solute diffusion and can be described by the following equation:

$$
C=c_{0}\left[1+\left(\frac{(1-\kappa)}{\kappa}\right) \exp \left(-\frac{\sigma_{x}}{D_{1}}\right)\right]
$$

In this equation, $C_{0}$ is the bulk concentration of che weld pool, $U$ is the solidification rate as measured by the dimensional novement of the 11quidsolid interface, $D_{1}$ is the solute diffusion coefficient in the 1 iquid, and $x$ is the distance in the liquid ahead of the solidification front. $x$ is the equilibrium solute partition coefficient of a specific solute element and is defined as the ratio of the solute concentration of the solld to that of the liquid at the solid/liquid interface. 
The partition coefficient $\alpha$ can have values greater than or smaller than one. In the case that $\alpha$ is less than one, soluce additions will lower the Iiquidus temperature of the alloy and the interdendritic liquid will have a higher solute content than the bulk material. With $\alpha$ greater than one, the solute addition w111 increase the liquidus temperature of the alloy and solute will be depleted from the interdendritic reglons. For most of the alloying elements added to fron and nickel alloy systems, $x$ is less than one, resulting In positive segregation in the interdendritic regions. $\alpha$ can be determined experimentally or from the equilibrium phase diagram of the alloy system.

The composition of the solute in the IIquid adjacent to the solid/1iquid interface is given by $C_{0} / x$. At distances further away form the solidification front, the solute concentration decreases exponentially and can be calculated using Equation 1. As solidification progresses, the solute partitions between the IIquid and solid according to $x$ and the solid/liquid interface advances carrying with it the amount of solute accumulated. As neighboring dendrites thicken and approach each other, the last liquid to solidify in the interdendritic region will have a composition equal to $2 C_{0} / x$, as is 11lustrated in Figure 1. This interdendritic solute redistribution occurs numerous times across a given grain. For example, in a typical submerged arc weld there are between four and six dendrites through a given columar grain. 


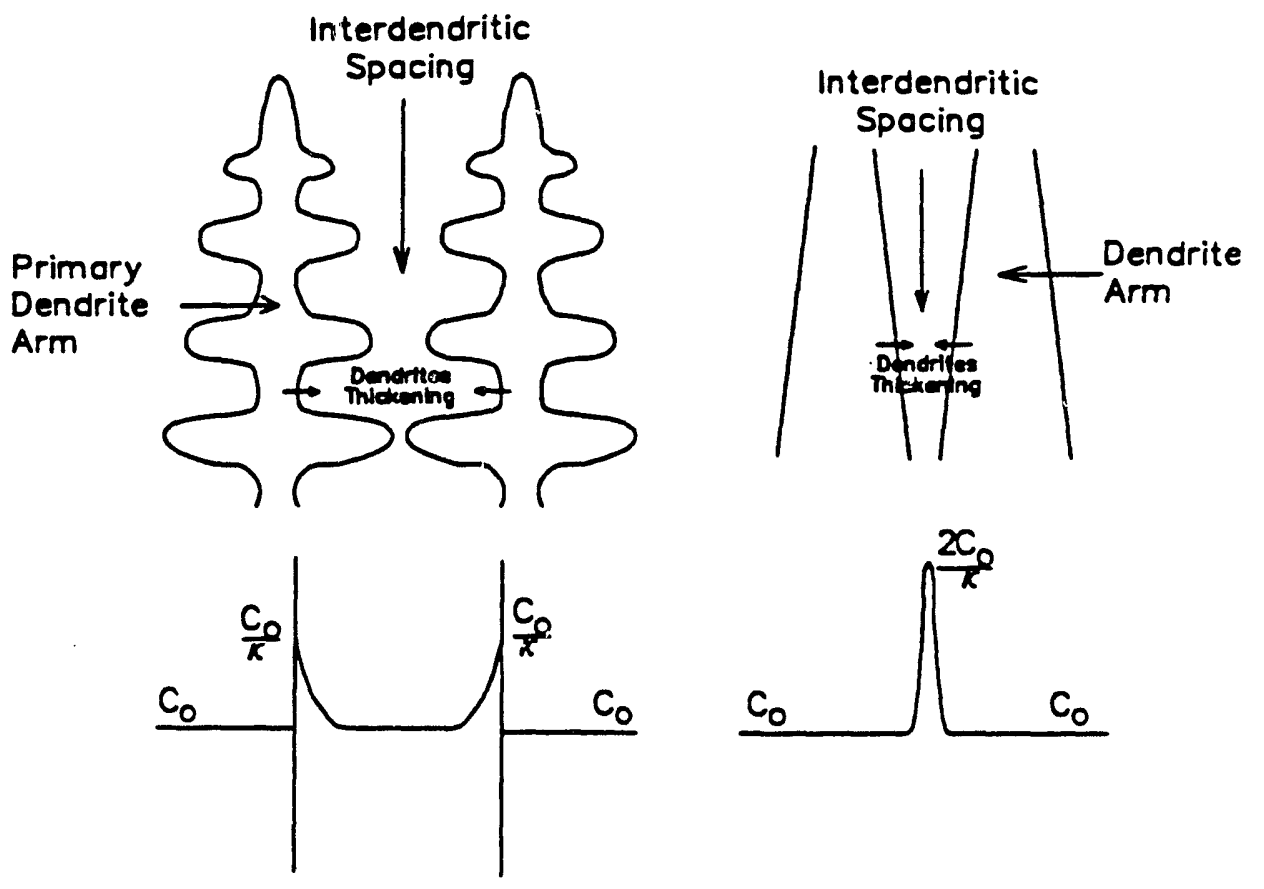

Figure 1. Schematic diagrams of dendrite arms and associated composition gradients. (a) Initial arm growth with high composition at the interface. (b) Entrapped liquid associated with final impingement of adjacent arns and the high composition which develops at the interface. This location of high solute content will have a high tendency to form inclusions (1). 


\subsection{REVIEW OF WORK COMPLETED ON PHASE TRANSFORMATIONS IN CORED STRUCTURE}

Weld metal possesses a solidification structure with composition and microstructure gradients. The presence of the gradients alters the typical methodologies for predicting phase stabllity. Both localized variations in alloy composition and potentially large localized composition gradients need to be considered in derermining the susceptibllity for development of a particular second phase.

Themodynamics and pyrochemistry have long $(2,3)$ been used in the prediction of weld metal composition. Based on the fact that the temperature of a weld pool is generally high, the reactions that occur in the molten metal are assumed to reach chemical equilibrium. However, welding processes are generally conducted at steady state conditions and not at equilibrium. The practice of using analytically determined weld deposit compositions in pyrochemical weld pool predictions leads to a concern, that of the role of solidification on solute element distribution and non-metallic inclusion formation in the weld metal.

For most of the alloying elements added to steels, $x$ is smaller than one, resulting in positive segregation in the interdendritic regions. In particular, elements such as oxygen and nitrogen will partition incensely to the liquid increasing their local concentration. The oxygen concentration at solidification of the interdendritic liquid can be over 10,000 ppm instead of the $300 \mathrm{ppm}$ determined analytically. It is reasonable, then, to expect that the interdendritic solute concentration plays an important role in determining the type, amount, and size of weld metal inclusions.

\subsection{Oxide Inclusion Formation in Gored Structure}

Non-metallic inclusions are found aligned in the interdendritic regions of low carbon low alloy steel weld metal. The inclusions, collected by the 
moving solid/liquid interface, delineate the prior solidification structure. Inclusions affect profoundly the phase transformation of weld metals. The type, size, and distribution of these inclusions, if adequately controlled, may assist in the development of the approprlate weld metal microstructure (48). Thus, the genesis of non-metallic inclusions in the veld pool needs to be better understood.

Consider the formation of an inclusion of the following general form:

$$
\chi \underline{M}+\underline{Y} \underline{N}+2 \underline{O}=M_{x} N_{y} O_{z}
$$

The free energy of formation, $\Delta G$, of $\mathrm{K}_{x} \mathrm{~N}_{y} \mathrm{O}_{z}$ can be written as:

$$
\Delta G=\Delta G^{0}+R T \ln \frac{\left[M_{x} N_{y} O_{z}\right]}{[M]^{X}[N]^{y}[O]^{z}}
$$

where [K], [N], and [O] are the solute activities in the IIquid, $x, y$, and $z$ are the stolchiometric constants from Equation 2 . [ $\left.\mathrm{M}_{x} \mathrm{~N}_{y} \mathrm{O}_{z}\right]$ is the activity for the specific inclusion and is assumed to have the value of one.

From Equation 1, the solute activities aheal of the 1iquid-solid interface can be written as:

$$
\begin{aligned}
& {[M]=\left[K_{0}\right]\left[K_{0}\right]\left[1+\left(\frac{1-\kappa_{M}}{\kappa_{M}}\right) \exp \left(\frac{-U x}{D_{L M}}\right)\right]} \\
& {[N]=\left[N_{0}^{\prime}\right]\left[N_{0}\right]\left[1+\left(\frac{1-\kappa_{M}}{\kappa_{M}}\right) \exp \left(\frac{-U x}{D_{L M}}\right)\right]} \\
& {[0]=\left[O_{0}^{\prime}\right]\left[O_{0}\right]\left[1+\left(\frac{1-\kappa_{M}}{\kappa_{M}}\right) \exp \left(\frac{-U x}{D_{L M}}\right)\right]}
\end{aligned}
$$

where $\left[\mathrm{K}_{0}\right],\left[\mathrm{N}_{0}\right]$, and $\left[O_{0}\right]$ are the concentrations of $M, N$, and 0 , $\left[\mathrm{M}_{0}\right]$,

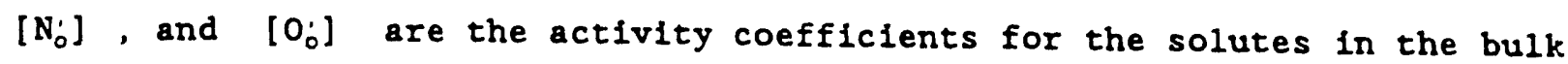


non-segregated liquid. Perturbing the system by increasing the solidification rate, 0 , wil increase the effective interdendritic solute concentrations each by their own amounts since each solute species has specific phase equilibrium and physical properties. Therefore varlations in $\kappa$ and $\Delta G$ wil also influence the size of the inclusions. As each type of inclusion will have its specific free energy of formation, each inclusion will have its own critical radius for nucleation.

From classical nucleation theory the critical radius for nucleation, $r_{c}$, is given by:

$$
r_{c}=\frac{2 \gamma V \phi}{\Delta G_{v}}
$$

where $\gamma$ is the interfacial energy between the second phase and the matrix phase, $\Delta G_{v}$ is the volume free energy per volume associated with driving force for the phase transformation, $\nabla$ is the specific volume and $\phi$ is the correction factor for heterogeneous nucleation.

Since weld solidification completes rapidly (typically, in seconds), the inclusion formed will experience only very limited growth and the critical radius of a specific oxide at nucleation is likely to be close to the final size, as observed in the weld specimens at room temperature. As the size of inclusions is also related to the type of inclusions, a particular microstructure, such as acicular ferrite, can also be identified with a specific inclusion (size and type).

However, in the welding literature, not only the size of inclusion are mentioned to be important, the number of inclusions within a particular size range is also reported to affect the microstructure $(4,8)$. It is expected, then, that the concentration profile of the solute reactants ahead of the solidification interface, which is a function of the welding experience 
through the solidification rate and the thermal gradient, influences the size and number of weld metal inclusions. The critical radius influences the rate of nucleation, I, which for a specific weld metal inclusion is given as:

$$
I=A \exp \left(\frac{-4 \pi r_{c}^{2} \gamma}{3 k I}\right)
$$

Therefore, $x$ for the specific solute elements can influence both the inclusion concentration and their size distribution.

Substituting Equations 4 to 6 into Equation 3, for the case of maximum solute accumulation, $2 C_{2} / \kappa$, that is, the concentration of the last interdendritic liquid (just prior to solidification),

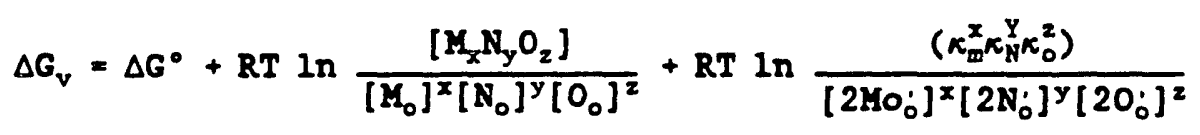

The third term in Equation 9 is a correction term for the free energy state due to segregation during solidification. It is a function of the equilibrium partition coefficients and activity coefficients of the solute elements participating in the deoxidation reaction.

The equilibrium partition coefficlents of the solutes $\left(\kappa_{i}\right)$ influence the concentration and ratio of reactants ahead of the solidification interface and thus the type of inclusions to be formed. Each type of inclusion has its own free energy of formation, $\Delta G$, which can be obtained from Equation 9.

\subsection{Martersite Formation in Cored High Alloy Steels}

Schaeffler ( 9 ) developed a constitution diagram for welding that has a nickel equivalent and a chromium equivalent as ordinate and abscissa, respectively, as shown in Figure 2. Though not immediately obvious, the low 


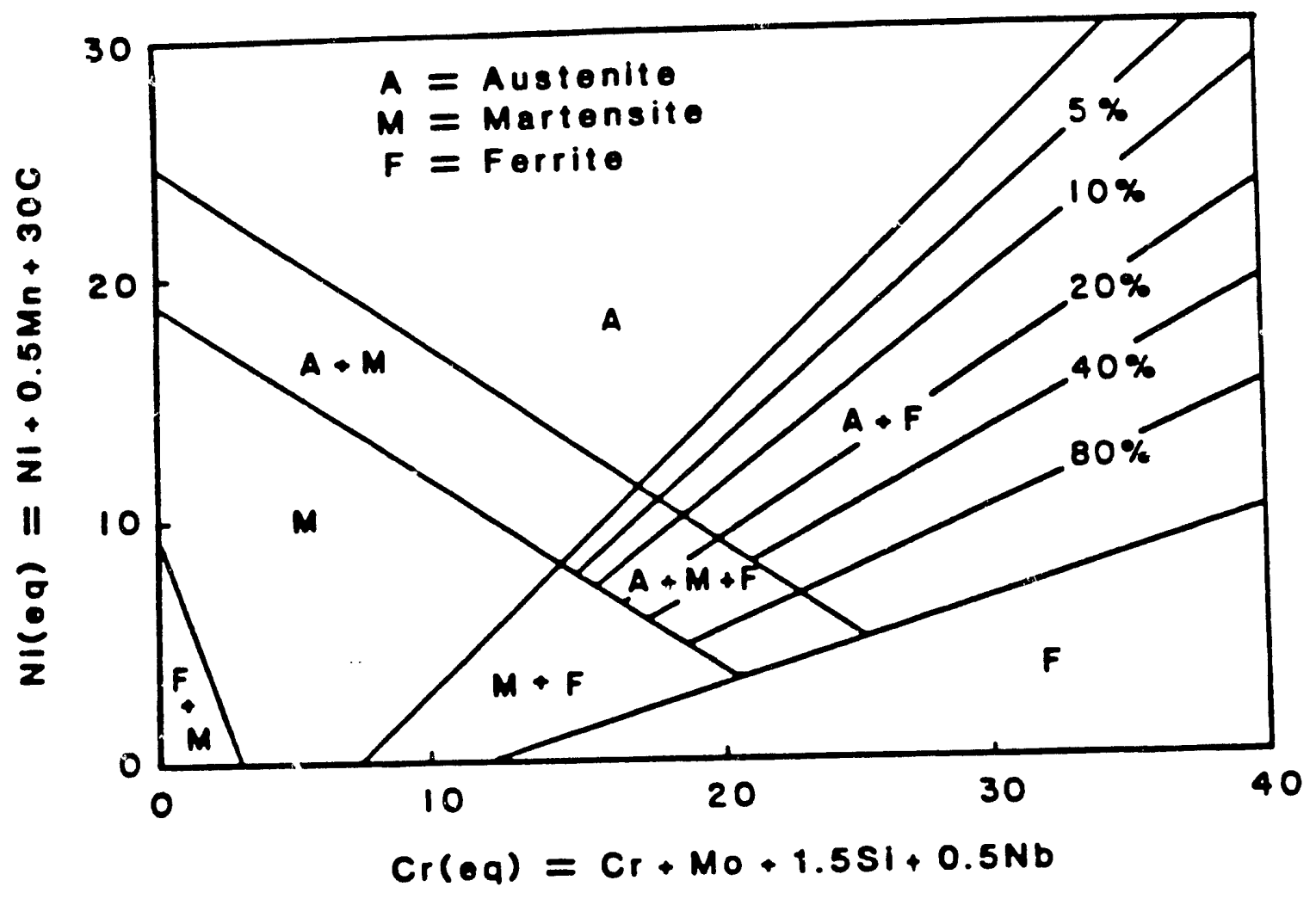

Figure 2. Schaeffler diagram for predicting weld metal microstructures. The prediction of Equation 2 evaluated at $20^{\circ} \mathrm{C}$ is indicated (9). 
chromiura side of this diagram (less than 18 wt. pct. chromium), is based on an assumed relationship between martensite start temperature, $H_{3}$, and alloy content, 1.e.,

$$
\begin{gathered}
\mathrm{K}_{\mathrm{B}}(\mathrm{C})=520-15.6 \mathrm{Cr}-20 \mathrm{NI}-10 \mathrm{Mn}-23.4 \mathrm{SI}-600 \mathrm{C}- \\
15.6 \mathrm{Mo}-7.8 \mathrm{Nb}
\end{gathered}
$$

With an $K_{8}$ temperature of $20^{\circ} \mathrm{C}$ in Equation 10 , the resulting compositional function predicts the astenite-martensize stability line in Figure 2.

It has become apparent that Equation 10 does not correctly predict microstructure over broad composition ranges in iron-chromium-nickel alloys (12-14). For example, alloys with 1 wt. pct. chromium have $x_{s}$ semperatures which are best predicted with the Andrews (10) equation and alloys in the range of 10 to $18 \mathrm{wt}$. Fct. chromium are better fit by the $\mathrm{M}_{2}$ equation of Elchlemann and Hull (11). These equations are given below:

Andrews (10) Equation:

$$
\mathrm{M}_{8}(\mathrm{C})=539-423 \mathrm{C}-30.4 \mathrm{Mn}-17.7 \mathrm{NI}-12.1 \mathrm{CI}-7.5 \mathrm{MO}
$$

Eichlemann and Hull (11) Equation:

$$
\begin{aligned}
M_{s}(F)= & 75(14.6-C r)+110(8.9-N 1)+60(1.33-\mathrm{Kn})+ \\
& 50(0.47-\mathrm{S} 1)+3000(0.068-(C+N))
\end{aligned}
$$

In Equations 11 and 12 , the magnitudes of the coefficients for each element indicate their contribution to promoting austenite stability. The more negative the coefficient, the greater the austenite stability (1.e., the lower the $M_{s}$ temperature) for a given alloy content. A comparison of the $y_{n}$ and $N i$ coefficients in Equations 12 and 12 Indicates that the effect of $M$ in more significant to $N 1$ in Equation 11; the opposite is indicated In Eqrition 12.

Self et al (12-14), after both reanalyzing the non-linear form of the Haurer diagram (15), a precursor of the Schaeffler Diagram, and evaluating over 160 data sets for a spectrum of wrought (homogeneous) alioy compositions 
from numerous investigators, established a more comprehensive $M_{s}$ temperature equation for high alloy steels:

$$
\begin{aligned}
& \mathrm{H}_{\mathrm{s}}(\mathrm{C})=521-14.3 \mathrm{Cr}-17.5 \mathrm{Ni}-28.9 \mathrm{Mn}-37.6 \mathrm{Si}-350 \mathrm{C}- \\
& 29.5 \% 0-1.19(\mathrm{Cr} \mathrm{N} 1)+23.1(\mathrm{Cr}+\mathrm{Ho}) \mathrm{C}
\end{aligned}
$$

By rearranging Equation 13:

$$
\begin{gathered}
\mathrm{NI}+1.65 \mathrm{Kn}+20 \mathrm{C}+0.07[\mathrm{Cr} \mathrm{NI}]=\mathrm{X}-0.82[\mathrm{Cr}+ \\
2.62 \mathrm{SI}+2.1 \mathrm{Mo}-1.6(\mathrm{Cr}+\mathrm{Mo}) \mathrm{C}]
\end{gathered}
$$

where $X$ is temperature dependent and is given by:

$$
X=\frac{\left[521-K_{8}(C)\right]}{17.5}
$$

By substituting a specific service temperature for $H_{3}$, one can obtain the compositional boundary line for stable austenite relative to martensite formation. Figure 3 lllustrates, on a modified Schaeffler type diagram, the shift in the martensite start-austenite stability ine.

This analysis indicates that to maintain an austenitic microstructure at lower application temperatures, higher alloy systems must be used. As a result, Equation 14 can be used to assist in the selection of wrought alloys which maintain an austenitic structure at a given cryogenic temperature.

The above analysis derived an $\mathrm{M}_{8}$ equation (Equation 13) from wrought or compositionally homogeneous data. To account for segregation, Self (13) modified Equation 13 by using coring factors derived frow the stainless steel segregation data of Takalo et al (16) and Surtala (17). Self reported that the miniaum for each alloying element would be given by:

$$
c_{\min }=\left(\frac{2}{(S+1)}\right) c_{\text {nom }}
$$

where $C_{\text {nom }}$ is the bulk elemental content and $S$ is the segregation ratio which equals 


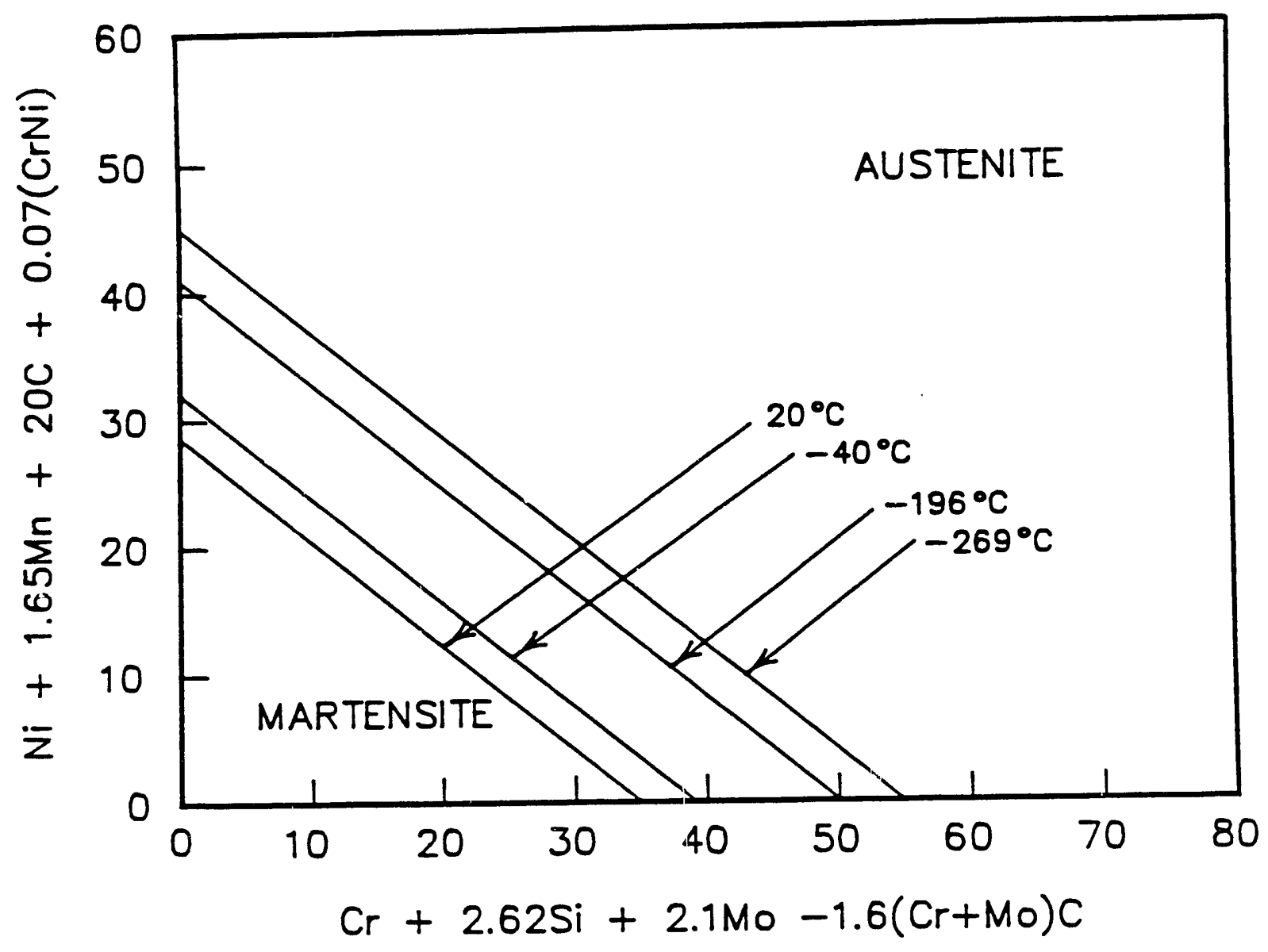

Figure 3. Austenite stability diagram for martensitic transformation of ferrous alloys at various temperatures. The lines represent predictions of Equation 6 . In Equation 6 the $C(C r+M o)$ term is only used if extensive carbide precipitation is probable (6). 


$$
S=\frac{C_{m i n}}{C_{n \infty m}}
$$

Self substituted Equation 16 for each specific alloying addition Into Equation 13 and reported a modifled $M_{s}$ equation for "as welded" steel weld metal:

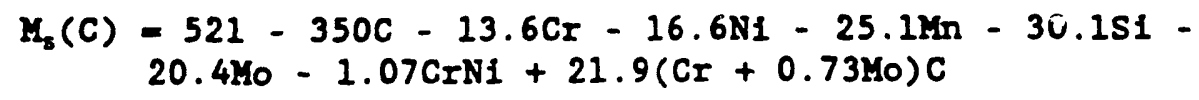

In a solidified structure Equations 13 and 18 describe the two extreme conditions. Equation 13 represents a fully homogenized weld metal while Equation 18 represents weld metal in the as-welded condition. The $M_{s}(C)$ will vary between the calculated values of Equation 18 and Equation 13 depending on the amount of homogenization due to post weld heat treatment.

\subsection{TCP Phase Formation in Cored High Nickel Allcys}

Cleslak et al (18), Carpenter et al $(19,20)$ and Ogborn (21) have recently evaluated the phase stability of high alloy weld metal. They illustrated that even though the bulk weld metal composition is known to be stable relative to second phase formation, microsegregation during solidification can produce locallzed poritions which have compositions that ar.e susceptible to phase transformations. Cleslak et al (18) used the New Phacomp analytical approach $(22,23)$ to demonstrute a methodology to predict weld metal stability in high nickel welds. The New Phacomp is a modified Phacomp analysis (24) which, through a more fundamental approach, allows for the influence of specific alloy elemental size, electronegative, and electronic configuration to be introduced into the phase stability criteria. The New Phacomp also considers the temperature dependence of phase stability. 
New Phacomp calculates the average energy in the metal $d-l e v e l$ ( $H_{d}$ ) for the solid solution structure by suming the contributions of each alloying element by its atomic fraction. This approach is analogous to electron-number No calculations in the original Phacomp analysis (24). That 1s,

$$
u_{d}=\sum_{i=1}^{n} M_{d i} f_{i}
$$

where $K_{d i}$ is the fundamentally determined metal d-level energy for a specific alloying element 1 and $f_{1}$ is the atomic fraction for the same element 1 . This compositionally determined $K_{d}$ value is compared to $K_{\text {dcrit, }}$ a critical value for

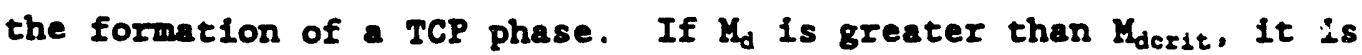
energetically favozable to form the second phase. For example, $\mathrm{H}_{\text {derit }}$ for sigma phase formation in high nickel alloys is given by:

$$
\mathrm{K}_{\text {derit }}=6.25 \times 10^{-5} \mathrm{~T}+0.834[\ln \mathrm{eV}]
$$

where $T$ is the temperature in Kelvin. This new modifled approach has been successful in predicting phase transformation in wrought homogeneous materials.

Cleslak et al (18) used the $H_{d}$ calculations for compositional variations at the subgrain level and determined $H_{d}$ as function of position along a compositional profile. They 1llustrated that if a localized region violates the $\mathrm{M}_{d}$ criterla these localized regions are susceptible to the formation of a second phase. This work showed that with a combination of microcompositional profiles and New Phacomp it is possible to determine if a speciflc high alloy weld metal will be unstable during high temperature service. Ogborn (21) demonstrated this practice for elght high nickel alloy weld metals.

Carpenter et al $(19,20)$ extended the New Phacomp analysis to include the influence of post weld heat treatment on weld metal phase stability. Since heat treatment can promote homogenization and reduce the amount of weld metal 
segregation, they developed a time-temperature dependent New Phacomp

expression for a sinusoidal microcoupositional profile which is given by:

$$
H_{d}(x)=\sum_{i=1}^{n} H_{d 1}\left[f_{n o m i}+\beta \sin \left(\pi \frac{x}{l}\right) \exp \left(-\frac{t}{T_{1}}\right)\right]
$$

where $C_{\text {nomi }}$ is the average bulk concentration of alloying addition $1, \beta$ is the compositional amplitude due to segregation, $l$ is the dendritic spacing, $T_{1}$ is relaxation time for a specific elepent 1 , and $t$ is the anseaing or high temperature service time. The relaxation time is inversely proportional to the apparent diffusivity of a specific element, and is given by:

$$
\tau_{i}=\frac{2^{2}}{D_{i} \pi^{2}}
$$

where $D_{1}$ is an apparent diffusivity coefficient and has the following temperature dependence:

$$
D_{i}=D_{o i} \exp \left(-\frac{Q_{1}}{k T}\right)
$$

where $Q_{1}$ is the activation energy for diffusion for element 1 .

It is now possible with knowledge of the microcompositional profiles and the specific rate coefficients for diffusivity to estimate the time at a given temperature for the alloy to homogenize to a degree where the localized $\mathrm{K}_{\mathrm{d}}$ value does not violate $\mathrm{M}_{\text {dcrit }}$ criteria.

This above approach utilized energy states with thermodynamic concepts and does not consider the kinetics for nucleation and growth of the second phase. The time for the nucleation of the second phase must be shorter than the time for the necessary degree of homogenization which bring $\mathrm{M}_{\mathrm{d}}$ below the $M_{\text {derit }}$ value. These time dependent competitive processes are schematically 
1llustrated In Figure 4 where the time to nucleate is the time to reach the cshape nucleation curve on this time-temperature plot and is compared with the time to homogenize. With a $T_{1}$ heat treatment, weld metal homogenization occurs before the nucleation of a second phase. It is apparent that with a $T_{2}$ heat treatment the second phase nucleates before sufficient homogenization. A consideration of the homogenization temperature in conjunction with the nucleation and homogenization curves shown in Figure 4 indicates that the Carpenter analysis $(19,20)$ can assist in the selection of post weld heat treatments.

\subsection{Role of Compositional Gradients}

The two previous analyses have considered the effects of average compositions, etther uniformly or locally, on phase stability. Compositional gradients are also known to influence the solid solution energy state and thus should affect phase stability. Cahn and Hilliard (25) considered the solution thermodynamics of non-uniform compositional systems and suggested that the region with compositional gradients have an added term, such that:

$$
\Delta G_{\text {grad }}=2 N \int G\left(\frac{d c}{d x}\right)^{2} d x
$$

where $\mathrm{N}$ is the number of moles per volume and $\mathrm{G}$ is an energy coefficlent. Equation 25 is integrated over the range of compositional variations. This increased solution energy alters the interfacial energy, $\gamma$, by the following expression:

$$
\gamma=\gamma_{\text {homo }}-2 N \int G\left(\frac{d c}{d x}\right)^{2} d x
$$




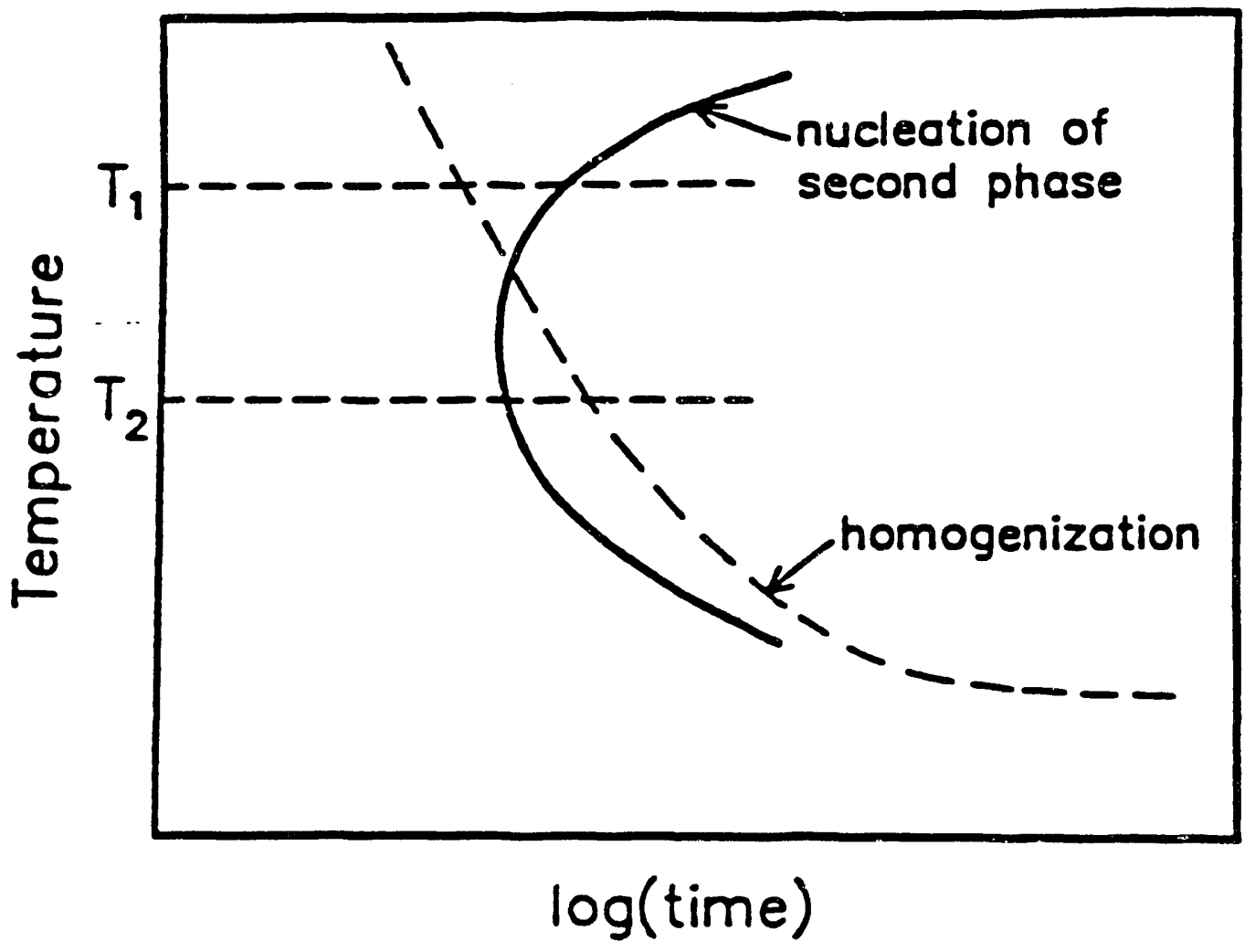

Figure 4. Schematic time-temperature diagram showing the effects of temperature on second phase nucleation and homogenization. 
and the total free energy of formation is given by

$$
\Delta G_{v}=\Delta G_{n o m}+\frac{4 N}{l} \int G\left(\frac{d c}{d x}\right)^{2} d x
$$

Substituting Equations 26 and 27 into Equation 7 results in a compositional gradient dependent expression:

$$
r_{c}=\frac{2\left[\text { hhowo }-2 N \int G\left(\frac{d c}{d x}\right)^{2} d x\right]}{\Delta G_{v}+\frac{4 N}{l} \int G\left(\frac{d c}{d x}\right)^{2} d x}
$$

For any given alloy system, the critical radius decreases significantly with an increase in the compositional gradient. A decrease in the critical radius will result in an increase in the rate of nucleation of the second phase. This concept suggests that second phase formation should be more easily achieved with "as cast" or "as welded" metal which possess large composition gradients. The analysis leading to Equation 28 further suggests that second phase particles should be at locations of maximum compositional gradients associated with grain boundarles and dendritic structure. An assessment of our understanding of phase stability in non-uniform compositional material was given at the AIME-TMS symposium on Joining Science Symposium (Cincinatti) In October, 1991. The influence of large compositional gradients on weld metal phase stability will be further researched through microstructural and phase characterization. This new effort will require collaboration with the national laboratorles, for ultra fine analytical capabilities are required. 


\subsection{WORK IN PROGRESS}

\subsection{Cracking Behavfor of Cored Structures}

The presence of microsegregation and other compositionally non-uniform conditions have been found to directly affect the mechanical properties of a wide variety of systems. For example, Johnson and Grimsley (26) Improved the stress corrosion cracking resistance of 17-7 PH stainless steel by homogenization, a heat treatment which eliminates compositional gradients. In weldments, both Savage et al (27) and Berry et al (28) reported that stress corrosion cracks in as-solidified microstructures follow the location in the microstructure where the concentration gradient is the steepest. To illustrate this point, Figure 5 shows the chromium microprofile in solidified stainless steel, along with the observed location (at the steepest point in the gradient) of a stress corrosion crack (28).

Other forms of cracking are also dependent on the ragnitudes of microcompositional gradients. For example, Chol et al (29) showed that postweld heat treatments decreased the susceptibllity of Monel Al2oy 400 weld metal to high temperature creep cracking. The decrease in cracking susceptibility correlated directly to changes in the microcompositional gradients due to the post-weld homogenization heat treatments.

These observations lead to fundamental questions about the role of microsegregation or compositional gradients on the local mechanical behavior and on the Initiation and propagation of cracks. In this research fundamental aspects of cracking in compositionally modulated structures are introduced. First-principle analyses are presented to 1llustrate the approach to the evaluation of both brittle and ductile cracking behavior in selected systems with controlled composition gradients. 


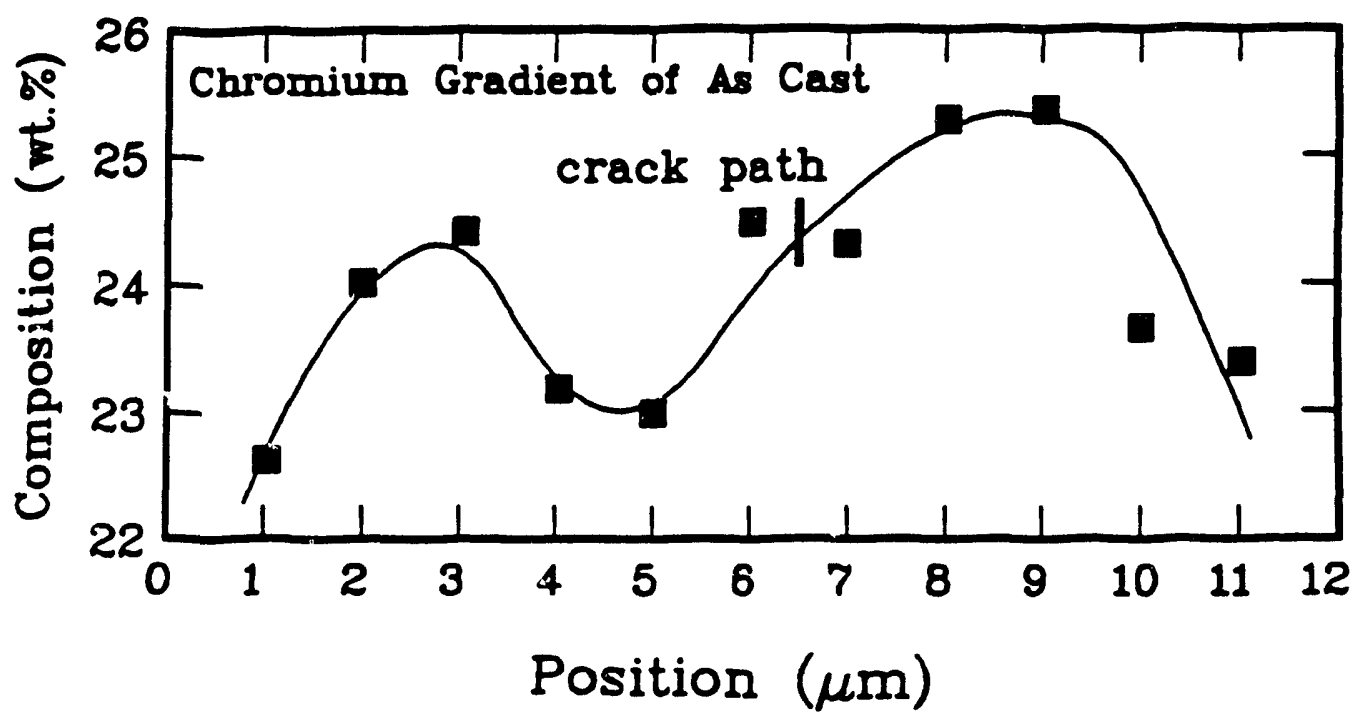

Figure 5. The microcompositional profile for chromium content across a stress corrosion crack of as-cast CK-20. Data were obtained on an unetched surface. Dashed line represents stress corrosion crack location (3). 


\subsubsection{Brittie Fracture}

The magnitude of the brittle fracture stress of a material is strongly dependent on the specific surface free energy as suggested by the Griffith Crack theory ( 30 ) and described quantitatively by:

$$
R_{c}=\alpha \sigma_{F}(\pi C)^{1 / 2}=\alpha(2 \gamma E)^{1 / 2}
$$

where $\sigma_{F}$ is the critical fracture stress, $\alpha$ is the geometric factor, $\gamma$ is the specific surfaje free energy, $R_{c}$ is the critical stress intensity factor, $c$ is the crack length, and $E$ is the modulus of elasticity. The specific surface free energy can be defined as the amount of the energy to create new surface. To correlate the specific surface free energy with fracture, it is necessary for the crack to form in a brittle manner, that is without energy being dissipated for deformation.

The specific surface free energy requires a reference energy state. For most materials this reference energy state is for a uniform (liomogeneous) material. This concept is illustrated in Figure 6 a where the energy difference between a reference energy state and the new surface is the specific surface free energy value to be used in the Griffith Crack Theory.

When crasidering the genesis of a crack through a compositionally nonuniform material a change in the reference energy state is required as shown in Figure 6b. Cahn and H1llird (25) introduced an approach to calculate the energy change of a material if it has developed a non uniform compositional state. Cahn and Hilliard (25) considered the local free energy associated with a non uniform system. They defined the local free energy quantitatively such that this specific energy, conceptually a specific interfacial energy, can be written as: 


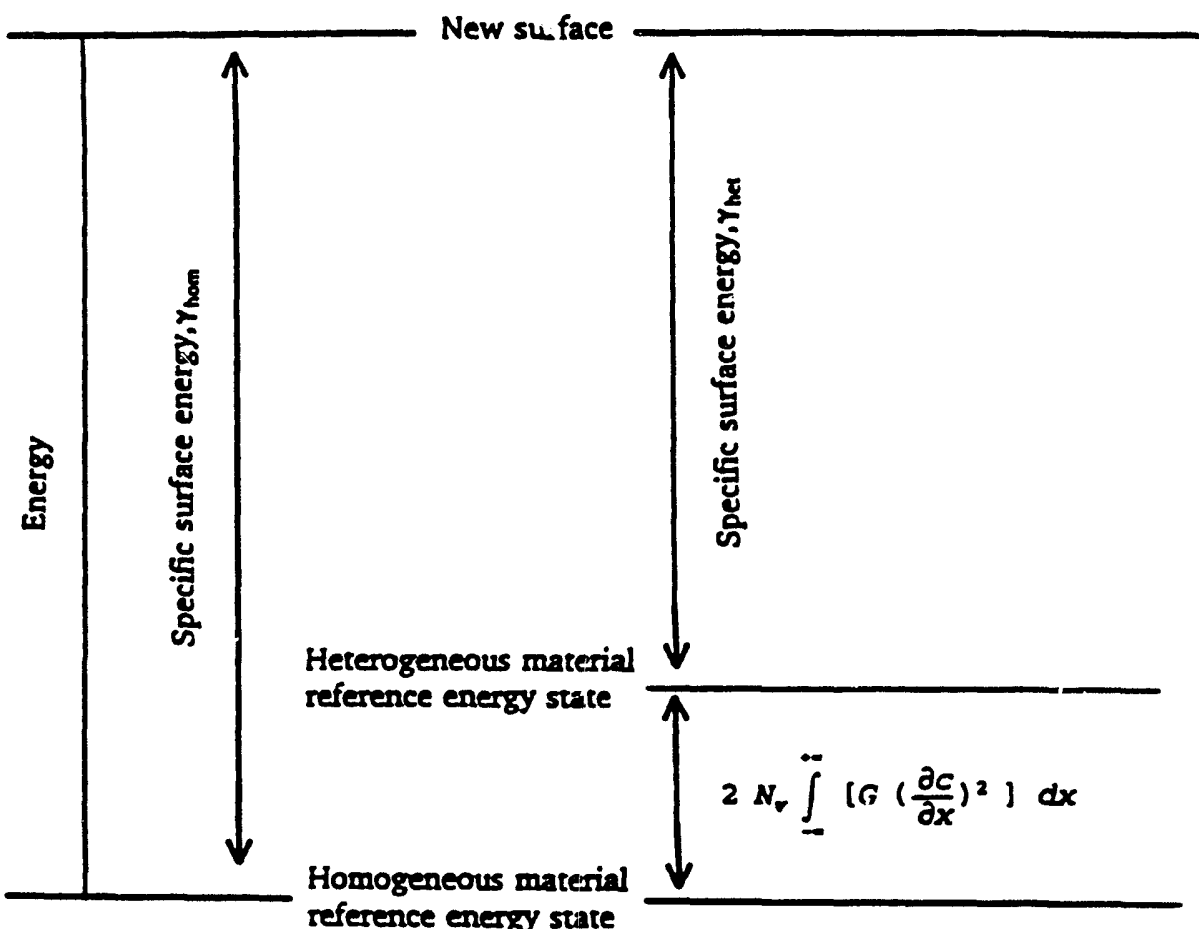

(a)

(b)

Figure 6. (a) Energy to create surface in a material in a compositionally uniform condition. (b) Energy to create surface in material in a compositionally non-uniform condition. 


$$
\gamma_{1}=N_{v} \int_{-\infty}^{+\infty} c\left(\frac{d c}{d x}\right)^{2} d x
$$

In Equation $30, N$ is the number of atoms per unit volume, $\mathrm{dc} / \mathrm{dx}$ is the composition gradient, $\gamma_{1}$ is the local specific interfacial free energy, and $G$ Is an energy coefficient which can be calculated from a specific solution model with knowledge of the necessary chemical thermodynamic and physical data for the alloy system.

With the analytical approach summarized in Equation 30 , the local specific free energy for this compositionally non uniform state gan be calculated and used to correct the reference energy state. This procedure is illustrated in Figure $6 \mathrm{~b}$. From Figure $6 \mathrm{~b}$ it can be seen that the specific surface free energy for a non uniform ( heterogeneous) material can be given by the following mathematical expression:

$$
\gamma_{\text {het }}=\gamma_{\text {how }}-2 N_{v} \int_{-\infty}^{\infty} G\left(\frac{d c}{d x}\right)^{2} d x
$$

where $\gamma_{\text {hom }}$ is the specific surface free energy for the homogeneous system and the second term is the Cahn-Hilliard expression which corrects the reference energy state for a non uniform condition. Equation 31 suggests that the local speciflc surface free energy is concentration gradient dependent. The steeper the concentration gradient the lower the localized specific surface free energy.

The specific surface free energy for the homogeneous system, $\gamma_{\text {hom, which }}$ is a necessary quantity for Equation 31, can be calculated as a function of alloy content by using the expression derived by Guggenheim (31): 


$$
\exp \left[-\frac{(\gamma \cdot A)}{k T}\right]=N_{1} \exp \left[-\frac{\left.\gamma_{1} A\right)}{k T}\right]+N_{2} \exp \left[-\frac{\left(\gamma_{2} A\right)}{k T}\right]
$$

In Equation 32, $A$ is the molar surface area $\left(A=1.612 \mathrm{~N}^{1 / 3} \mathrm{~V}^{1 / 3}\right), \gamma_{1}$ and $\gamma_{2}$ are the specific free energies of the Individual elemental components of the system, and $\mathrm{kT}$ has Its usual słgnificance.

\section{1 .2 Ductile Fracture}

The presence of microsegregation can affect ductile fracture mechanisms at both low and high temperatures. With respect to low temperature deformation mechanisms, the local composition controls the stacking fault encrgy, which In FCC materials controls dislocation structure and movement. For example, fatigue of compositionally uniform alloys has been found to be related to the magnitude of its stacking fault energy $(32,33)$. If the stacking fault energy is high, the dislocations can easily cross slip around obstacles and thereby promote slip band formation and have a significant plastic zone at the crack tip. This type of slip band behavior has been called "wavy" and has been reported (34) to lower the fatigue resistance. Low stacking fault energies make cross slip more difficult and constrict the dislocation motion to planar flow. This type of slip band behavior has been classified as "planar" and may hinder the fatigue process.

The influence of the compositional gradients on the formation of stacking faults, and thus on fatigue, can be evaluated following the procedures discussed above for stress corrosion cracking. Specifically the stacking fault energy in a compositional gradient can be expressed as the sum of the stacking fault energy of an alloy in the homogeneous condition (35), $\gamma_{\mathrm{SF}}(\mathrm{hom})$, and the increase in the energy due to the compositionally non 
uniform condition. Thus, the stacking fault energy for a heterogeneous system can be expressed as:

$$
\gamma_{g f}(\text { het })=\gamma_{E f}(\text { hom })+2 N_{v} \int_{0}^{x_{s f}} G\left(\frac{d c}{d x}\right)^{2} d x
$$

The second term is descrtbed using the Cahn-Hilliard expression (Eq. 30), $x_{3 f}$ is the width of the stacking fault, and (dc/dx) is the compositional gradient through the stacking fault region.

Equation 33 describes how both the stacising faulty energy and the energy associated with the segregation change the reference energy state of the materlal. This is 11lustrated in Figure 7.

It is apparent based on this model that the stacking fault energy varies across the cored metal and that the locations of the steepest compositional gradients are most likely to produce extremes in stacking fault energy. These locations are predicted to have the least fatigue resistance and would be the preferred site for fatigue crack propagation.

The applicability of Eq. 31 was considered in tis current research program in an analysis of the path of preferred crack propagation in a copper6.4 wt. pct. nickel casting. Fatigue crack growth was measured with compact tension samples with notches orlented to induce crack growth parallel to the solidification direction. The fatigue crack path was evaluated with both light and scanning electron microscopy. In addition, the as-cast segregation in the area of the fatigue crack was measured with energy dispersive spectroscopy (EDS). To illustrate the relationship between crack path and compositional gradient, the variation in nickel content on a traverse across the fatigue crack (as measured on a mounted and polished sample which was stopped during the stable growth zone) is presented in Figure 8 . Significant 


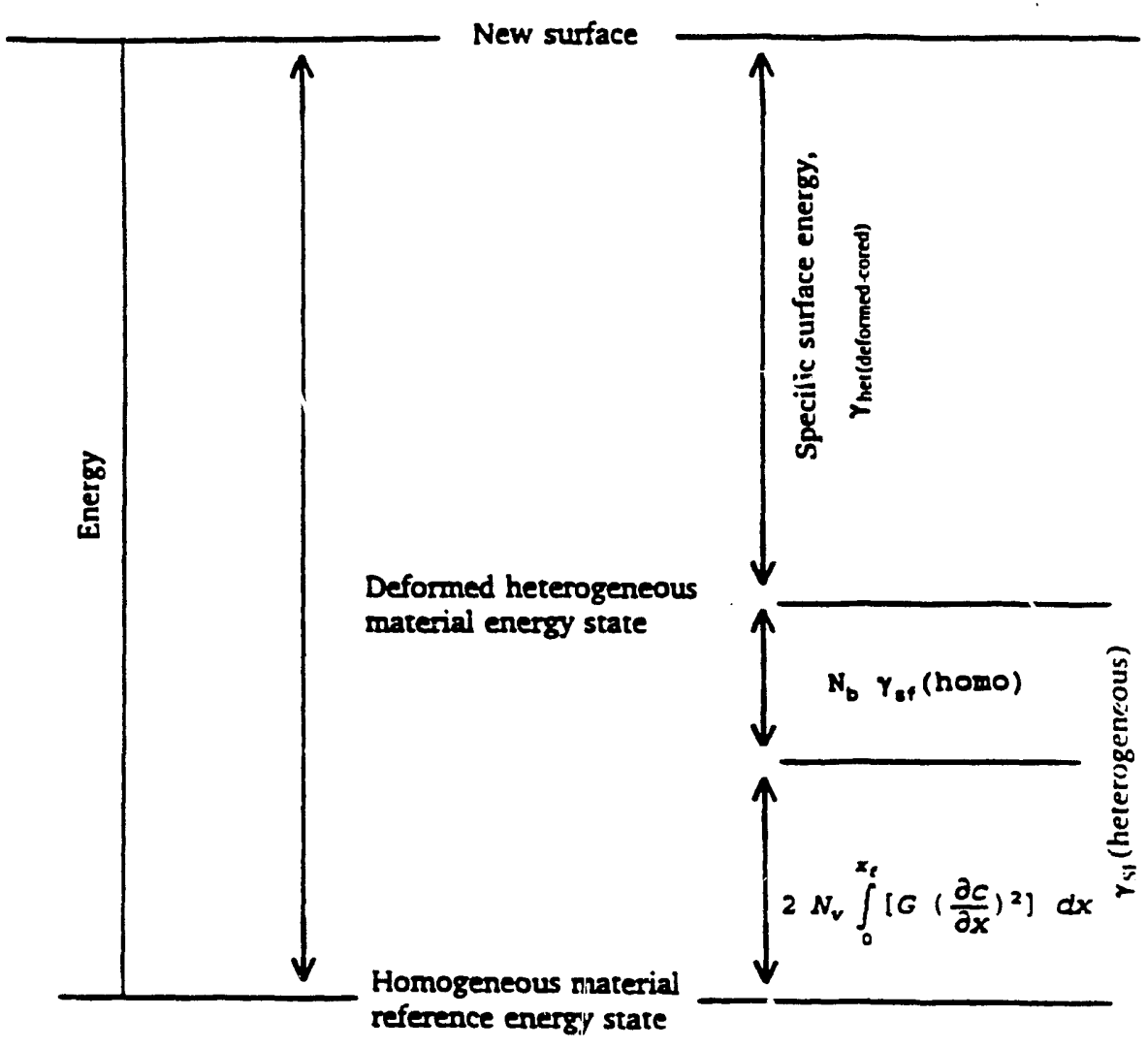

(a)

(b)

Figure 7. (a) Energy to create surface in a homogeneous material. (b) Energy to create surface in a segregation and deformed material. 


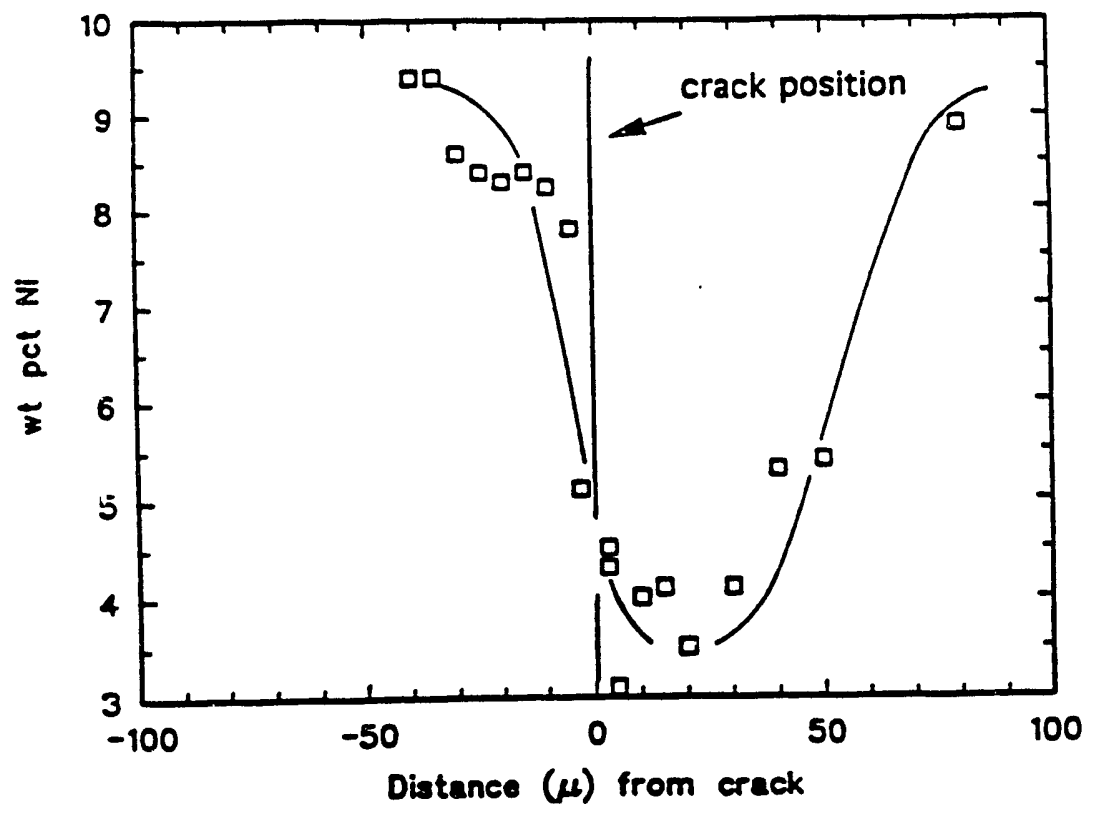

a.

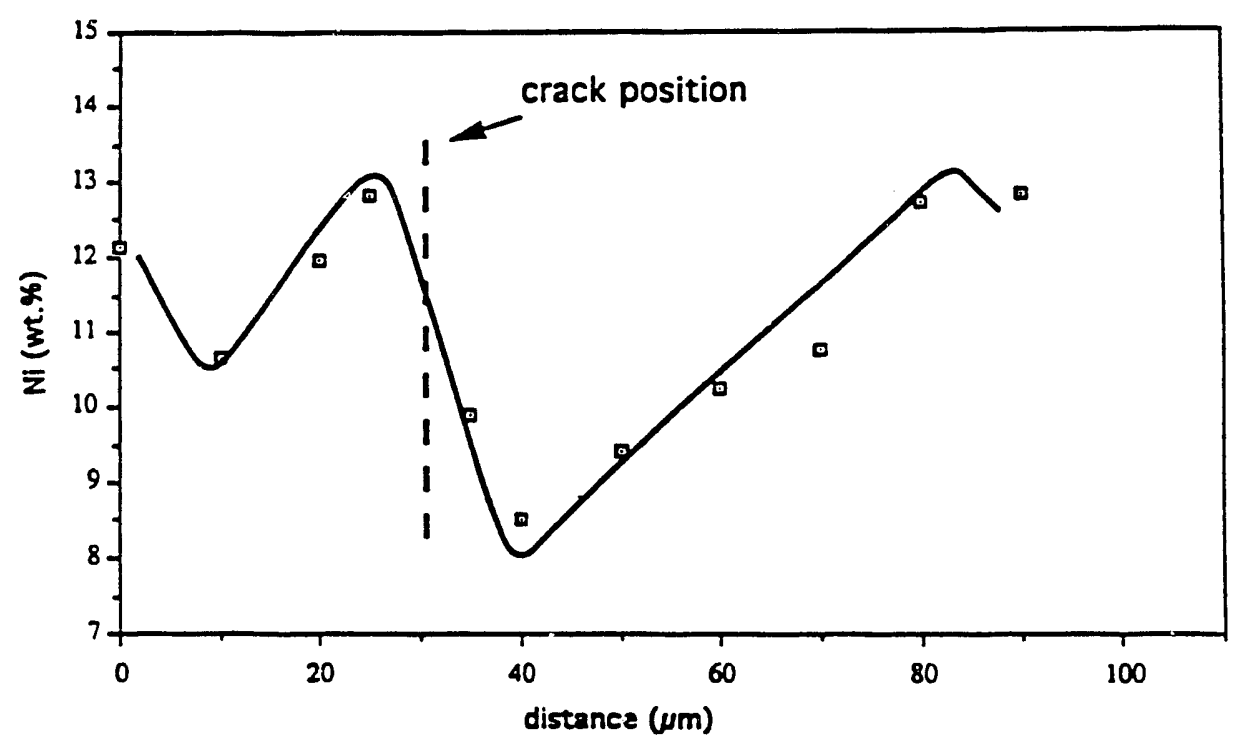

b.

Figure 8. The variation of nickel content across fatigue cracks (located at the zero position) in compact test specimens. (a) an as-cast polycrystal copper +6.4 wt pct nickel alloy. (b) a single crystal of copper +10 wt. pct. nickel. Notice that for each cases cracking occurs in the region with compositional gradient. 
variations in nickel content are shown and the crack location is shown to correlate with the location of the highest composition gradient. The correlation between crack growth and compositional gradient supports the analysis which indicates that fatigue crack growth resistance is directly related to the local compositional gradient, and thus the local stacking fault energy.

The preliminary fatigue cracking investigation was performed in directionally solidifled copper-6.4 wt pct nickel cast material where the loading and specimen configuration was orlented to promote cracking parallel to the solidification direciion. Figure 8 a illustrates that the crack preferred the locations of steep concentrations, not at the lowest nickel content as may be expected based on a strength consideration.

To perform the detailed analysis required to verify the noted cracking behavior and to determine a mechanistic understanding, single crystad. copper108 nickel specimens, produced by GE Engine Research Laboratory, wer: evaluated. A special CT fracture specimen was developed to minimize the amount of the specially prepared single crystal material which was required. When tested, the iarigue crack was again found to be oriented along the dendrites and propagated in regions of high compositional gradients. The compositional profile across the fatigue crack in these single crystal specimens is shown in Figure $8 \mathrm{~b}$. These unique cracking features were reported at the ASM HIgh Temperature Alloy Conference at Geneva Lake, WI (October 1991). Work is continuing on characterization of the cracking features relative to compositional varlations. The compositional profiles of the single crystals are being varied through partial homogenization. Electron microscopy is being applied to characterize the defect-structure relationships in the regions with high compositional gradients. It is anticipated that 
during the next contract period a better mechanistic understanding of deformation and fracture in uniform material will be achleved.

\subsection{The Effects of Dynamic Composition Gradients on the Creep Behavior of Weid Metal}

Diffusion induced changes in local composition gradients are considered In this study of the high temperature creep behavior of laminate composites. The laminate composites are designed to simulate both the dimensions and composition gradients associated with coring induced on solidification in weldments and castings. Previous studies $(36-41)$ have show that the hightemperature mechbical properties of materials with composition and microstructure gradients depend sensitively on the magnitude of the gradient. In the previous studies on the creep behavior of weld metal and laminate composites $(36,38-40)$, the gradients were established prior to testing by various annealing treatments. Due to the temperatures used in the heat treatments it was assumed that the gradients were stable during testing. In the current study the effects of dynamic changes in the composition gradients during testing are considered. As with the previous work $(36,38-40)$, alloys based on the $\mathrm{Ni}-\mathrm{Cu}$ system were chosen for this study. The primary objectives of this study are to evaluate the effects of time dependent changes in composition gradients in ideal laminate composites by considering the interaction of stress and diffusion between layers, the effects of interdiffusion on creep deformation, and the effects of excess vacancies generated from unequal diffusion rates on creep deformation and microstructure stability. The program involves four primary parts:

1. Develop a theoretical analysis to predict composition differences between adjacent layers to suppress significant diffusion induced pore formation in laminate composites of $\mathrm{NI}$ and $\mathrm{Ni}-\mathrm{Cu}$ solid 
solution alloys subj:stnd to high temperature exposure;

verification of predictions with metallography of annealed composites.

2. Fabrication of ideal laminate composites with alternating layers of $\mathrm{NI}$ and $\mathrm{NI-Cu}$ solid solution alloys.

3. Experimentally determine the effects of stress and temperature on composition gradient changes and the high temperature creep behavior of the experimental laminate composites.

4. Theoretically predict, based on an FEM analysis, the effects of stress and temperature on the high temperature creep behavior of laminate composites.

During this reporting period, tasks 1 and 2 have been completed and significant progress on tasks 3 and 4 have been obtained.

Based on the work of Balluffi and Seits $(42,43)$ an analysis was developed to predict the critical composition difference to prevent diffusion Induced vold formation between a laminated composite of pure nickel and nickel-copper solid solution alloys. The analysis, which is currently being prepared for publication, predicted that no volds would form if the copper content of the nickel-cupper solid solution alloy was kept below 40 atomic percent. Therefore, to experimentally evaluate the predictions of this analysis and to prepare samples for subsequent creep studies, laminated composites between pure nickel and five nickel-copper solid solution alloys (Ni-108Cu, Ni-208Cu, Ni-308Cu, Ni-408Cu, 508Ni-508Cu) were fabricated. The solid solution alloys were received from Inco Alloys International in the form of $13 \mathrm{~mm} \times 108 \mathrm{~mm} \times 711 \mathrm{~mm}$ hot rolled plates. The plates were hot and cold rolled at the Colorado School of Mines to produce $0.4 \mathrm{~mm}$ thick sheets. Forty $0.4 \mathrm{~mm}$ sheets of each solid solution alloy were alternately stacked with 0.4 mm pure nicliel sheets and were vacuum encapsulated in a stainless steel 
container. The compacts were hot and cold rolled to produce 1.65 mm thick laminate composites of each alloy combination. To evaluate the predictions of the vold formation analysis, coupons of each composite were annealed at $1000^{\circ} \mathrm{C}$ for 30 minutes and examined using both 1 ight and electron microscopy techniques. Figure 9 shows representative micrographs of two laminate composites after annealing. No volds were observed in composite; which Included less than $308 \mathrm{Cu}$, an observation which was consistent with the theoretical predictions.

High temperature creep testing of the laminate composites in the asrolled condition is underway. Creep tests have been performed at three stresses $\left(65,85\right.$, and $104 \mathrm{MPa}$ ) at temperatures of $427^{\circ} \mathrm{C}, 527^{\circ} \mathrm{C}$, and $627^{\circ} \mathrm{C}$. To 11lustrate the effects of layer composition on the high temperature creep behavior Figure 10 shows the dependence of the creep rate evaluated at various plastic strains on the copper content in the $\mathrm{Cu}-\mathrm{N} 1$ solid solution layer at $627^{\circ} \mathrm{C}$. These results indicate that the creep behavior of the composites depends directly on the laminate layer compositions.

Composition gradients, both before and after creep testing, have been obtained with Energy Dispersive Spectroscopy (EDS) techniques. As an example, Figure 11 shows the composition gradients after 100 hours of creep testing at $627^{\circ} \mathrm{C}$ for two laminate composites comprised of alternating layers of $N 1$ with eIther N1-488Cu or Ni-298Cu. Both samples, which showed no observable gradients prior to testing, exhibited significant interdiffusion during creep testing. The effects of interdiffusion and creep testing on the fine microstructure which develops across the interfaces is being evaluated with transmission electron microscopy (TEM) at the Solar Energy Research Institute in Golden Colorado. Techniques for thinning the layered structures bave been developed at SERI and initial micrographs have been obtained. In addition, collaborat!ve work with the Oak Ridge National Laboratory is underway to 




a.

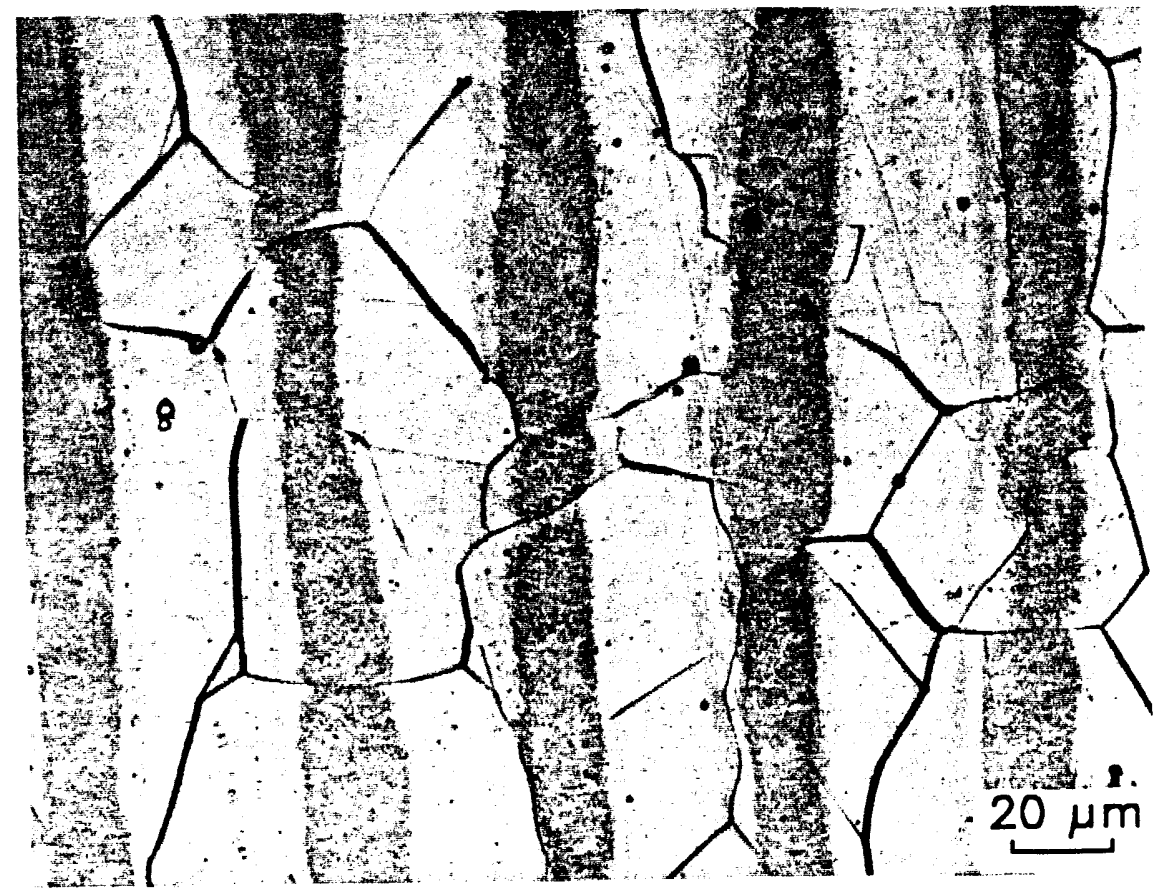

b.

Figure 9: Light micrographs of laminate composites with alternating layers of $\mathrm{Ni}$ and $\mathrm{Ni}-\mathrm{Cu}$ solid solution alloys after annealing for $30 \mathrm{~min}$. at $1000^{\circ} \mathrm{C}$. In (a) the light $\mathrm{Ni}-\mathrm{Cu}$ solid solution layer contains $8.9 \% \mathrm{Cu}$ and in (b) the layer contains $18.9 \% \mathrm{Cu}$. Etched in a 50:50 nitric acid and methanol solution. 

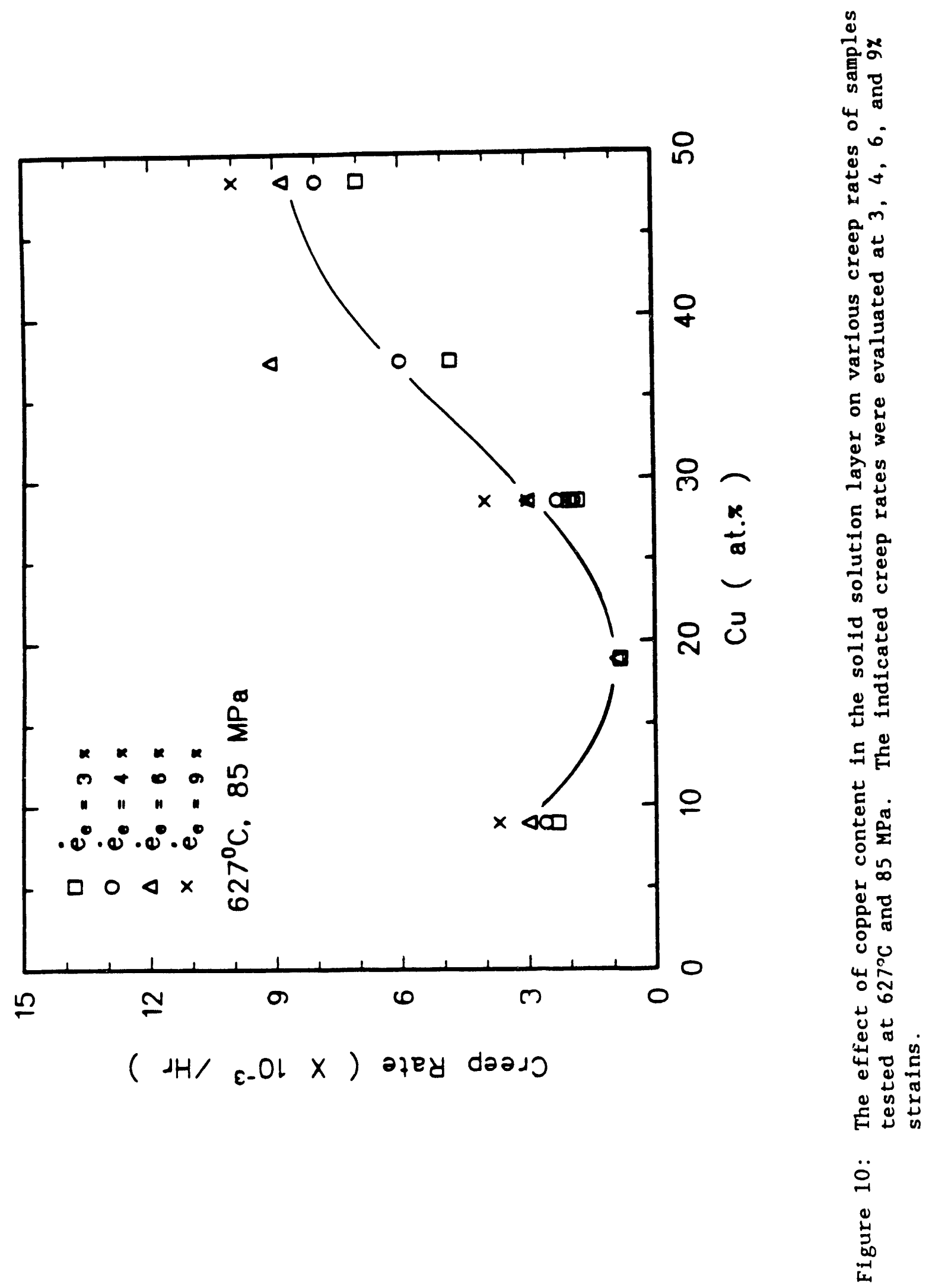
further characterize, with fine microprobe analysis, the nature of the composition gradients in the deformed samples.

The composition measurements shown in Figure 11 will be utilized in confunction with the proposed three-stage analytical interdiffusion model which has been developed in this study as well as with the FEM numerical analysis currently under development. Inlt1al FEM analysis utilized NIKE2D. However the method was shown to not properly describe the time dependence of both creep and composition changes. An FEM code based on a viscoplastic strain model w111 be modified to incorporate the composition gradients. This analysis, which is underway in conjunction with the Engineering Department at the Colorado School of Mines, uses a Lagranglan scheme to account for large strains. However, a simplified Iinear range of 58 total strain is considered in this study.

The results of this study on creep in composites with controlled composition gradients, will be submitted to the 1992 Gatiinburg International Welding Conference and have led to several conclusions:

1. Laminate composites of pure nickel and NI-Cu solid solution alloys heve been fabricated and shown to exhibit predicted properties.

2. The resulting creep data depend on dynamic concentration gradients.

3. The composition profiles across the interfaces have been measured before and after creep. The results will be used for the verification of a 3 -stage analytical diffusion model.

4. Modeling based on both FEM and mechanistic behavior is in progress and the results will be correlated with measured creep properties. 


\subsection{Particulate Metal Matrix Composite as a Weld Deposit}

This investigation was performed to study the possibilities of making particulate metal matrix composite weld deposits with austenitic stainless steel base metal. The weld deposit would have a high volume fraction of uniformly distributed insoluble ceramic or refractory metal particles. The particles would be added into the weld pool through the axc by way of the core of a tubular welding flller wire. Both gas metal arc and gas tungsten arc welding procedures have been used to study the effect of the welding process on the particle transfer and recovery.

One application for this kind of weld deposit would be in welded assemblies for high temperature service, such as bollers, heat exchangers and power plants. Stalnless steel weld metals tend to fail in high service temperatures with creep fracture (14). Hard, Insoluble second phase particulates of a specific size distribution and with a unform spatial distribution in the weld metal act as obstacles against dislocation movement in the microstructure and increase the creep 1 ife $(44,45)$. The strengthening of the microstructure with hard particulates follows the rule of mixtures. According to the rule of mixtures the mechanical properties of the composites are enhanced with increasing the fraction of the reinforcing phase having higher strength values than the matrix (47).

The creep resistance of metals can be significantly improved by a homogeneous dispersion of second phase particles which can serve as effective obstacles to the dislocation motion ircreasing the creep resistance of the metal. When subjected to an external load, the particles tend also to carry a higher stress, thereby reducing the stress level experienced by the matrix. Thus, the creep resistance of particle reinforced alloys is improved by these two mechanisms: bypassing of the particles by dislocations and reduction of creep rate associated with the stress distribution (46). 
The creep rates decrease with increasing particle diameter at low stresses below the yleld stress. A decrease in creep rate with increasing particle diameter has been predicted when creep is assumed to occur by dislocation climb over the particles at stresses below the Orowan bowing stress. The increase in creep resistance with increasing particle diameter at low stresses is believed to be a result of larger particles providing more effective obstacles to sliding $(45,47)$.

Creep resistance increases with increasing particle size until the critical spacing and size are reached when then the dislocations are able to bow between rather than cut through the particles. Above the critical size the creep rate increases as bowing becomes progressively easier with increasing size and spacing of particles. When tested at high stresses, a minimum in steady state creep rate is observed for particle dispersions resulting in highest room temperature hardness (45).

The influence of particles on the creep rate has been taken into account by introducing a friction or threshold stress, $\sigma_{B}$ into the power law of steady state creep rate:

$$
\epsilon_{s}=B^{\prime \prime}\left(\frac{\sigma-\sigma_{B}}{E}\right)^{n} \exp \left(-\frac{Q_{c}}{R T}\right)
$$

where $\sigma$ is the applied stress, $n$ is the stress exponent, $Q_{c}$ is the activation energy for creep, $B^{\prime}$ is a constant and RT has its usual significance (45). $\sigma_{B}$ is the Orowan stress and is calculated by Peterseim and Sauthoff (48) as:

$$
\sigma_{B}=\frac{\sqrt{3} * 1.13}{2 \pi}\left(\frac{d}{4} \frac{G}{\lambda}\right)
$$

where $d$ is the diameter of particles, $b$ is the Burgers vecior and $\lambda$ is the mean distance between particles. 
It has been found that the introduction of the threshold stress, $\sigma_{B}$ and the elastic modulus correction in creep rate equation brings the value of stress exponent, $n$, Into the range found for the matrix material without particles and the value of $Q$ close to the activation energy for self-diffusion (49).

\subsubsection{Solidification and Fluid Flow Considerations}

The distribution of particles in metal matrix composites which were manufactured by a casting technique depends on the nature of the interaction between ceramic particles and the growing solidification front. Basically, when a moving solidification front intercepts an insoluble particle, it can either push or engulf the particle. Engulfment occurs through growth of the solid over the particle, followed by enclosure of the particle in the solid. Two or more solidification fronts can converge on the particle if the solidification front breaks down into cells or dendrites (50).

Thlmann et.al. (51) reported the existence of a critical interface velocity, $\nabla_{c r}$. Below critical velocity particles are pushed into the last freezing regions and above particles are engulfed. The critical velocity has been experimentally found to depend on particle radius, $x$, according to:

$$
V_{c r} I^{n}=\text { constant }
$$

where the exponent $n$ ranges from 0.28 to 0.90 .

The motion of particulates in the weld pool can be studied using fluid mechanics models which are based on 'orce balance on a particle in the pool (52). The velocity of the liquid, $V_{1}$, to suspend a particle with radius $I_{p}$ under a constant acceleration when the density of liquid is less than the density of particles can be determined. This suspension velocity of the 
liquid which contains spherical particle with a particle density greater than the fluid is deduced from the Stokes' law and is given by Lajoye and Suery (53):

$$
v_{1}=\frac{2 r_{p}^{2}\left(\rho_{p}-\rho_{1}\right) 8}{9 \eta}
$$

where $r_{p}$ is the radius of the particle, $\rho_{1}$ and $\rho_{p}$ are the densities of IIquid and particle, respectively, $\eta$ is the viscosity of the liquid and 8 is the acceleration.

When the density of the liquid is greater than the particle, the sign of the friction force is opposite and the equation for the steady state velocity of the liquid, $\nabla_{2}$, is given by equation 38 .

$$
v_{2}=\frac{2 r_{p}^{2}\left(\rho_{1}-\rho_{p}\right) 8}{9 \eta}
$$

When the velocity of the weld pool is greater than the calculated steady state liquid velocity, the anslysis suggests that the particles will go with the stream and particle dispersion is expected. If the weld pool velocity is less than the steady state Ilquid velocity, the particulates will sink or float depending on their density and dispersion is not expected. When the particles do not disperse there is a greater probability of agglomeration.

\subsubsection{Experimental Design and Procedures}

The effects of density and size of the particulates were determined in this investigation using different powder materlals. Processing parameters for acceptable solidification of the weld deposits with second phase particulates were investigated. Several specific questions were addressed in this investigation. 
(1) Can particulates be effectively transferred through the arc?

(2) What is the particle distribution and how can 1: be controlled?

(3) What influence do the particle size variation and density have on the uniform distribution, dissolution loss and transier loss?

(4) What is the nature of MMC weld deposit?

(5) How would composite consumables be made?

(6) That rules would be necessary to design consumables for desired properties?

AISI 310 stainless steel was chosen for the matrix material for the particulate metal matrix composite welding consumable because of its applications as a high temperature material and because it solidifies with fully austenitic mode. The latter criterion makes the solidification investigation simpler since no duplex structure (austenitic-ferritic) would be expected during the solidification of weld pool with ceramic particulates.

The powders used to produce second phase particles in the weld pool were chosen with density criterion relative to the density of the stainless steel matrix. For the powder materials tungsten, tungsten carbide, niobium carbide and titanium carbide powders were selected. All powders have been used successfully with steels and stainless steels to produce second phase particulates in the matrix by several researchers (54-57) and were chosen based on the requirement that their hardness and melting temperatures would be higher than those of AISI 310 stainless steel.

For the welding processes gas metal arc and gas tungsten arc welding procedures with argon shielding gas were chosen to study the transferability of the particulates through the arc and the recovery rate of particles in the weld pool. The welding wire that was used in these experiments was manufactured from $25 \mathrm{~mm}$ diameter AISI 310 stainless steel tube which was filled with the appropriate powcier and then hot and cold rolled to produce 
welding wire. The weld deposits were made on a $12.5 \mathrm{~mm}$ thick AISI 304 stainless steel plate with a $90^{\circ}$ angle V-groove.

With sufficient particle size, the particulates can produce a second phase in the weld metal that can increase its high temperature creep 11 fe. High melting point of the potential second phase particulates minimizes the dissolution into the matrix weld pool during velding. The physical properties of the matrix and the powder materials are presented in Table I.

Tungsten powder was used with different particle sizes to study the effect of the particle size distribution in the consumable on the spatial distribution of the particulates in the weld deposit. The size categories of tungsten powders that were investigated have been listed In Table II.

The first two tungsten powder sizes that were investigated were $0.5 \mu \mathrm{m}$ and -100 Mesh $(<140 \mu \mathrm{m})$ powders. The tungsten powder was uncoated in these experiments. The remaining tungsten powders in Table II were used with glass coating on the surface produced by the sol-gel process. Tungsten carbide, niobium carbide and titanium carbide powders were researched each with one specific average particle size, 1,2 and $0.5 \mu \mathrm{m}$, respectively. These powders were uncoated.

\section{Sol-Gel Coating Process}

Tungsten powder was found to have a high dissolution rate in the stainless steel weld pool. High dissolution rates were experienced in the first two experiments with $0.5 \mu \mathrm{m}$ and $-100 \mathrm{Mesh}(<149 \mu \mathrm{m})$ size particulates. The sol-gel process, which can produce ceramic material by chemical processes, was used to produce $\mathrm{SiO}_{2}$ glass coating on the surface of the particulates to minimize the dissolution behavior by forming a physical barrier between the liquid metal and the particle (58). 
TABLE I - Physical Properties of the Welding Wire Matrix and Powder Materials (66)

\begin{tabular}{|c|c|c|}
\cline { 2 - 3 } \multicolumn{1}{c|}{} & & Melting Temperature \\
\cline { 2 - 3 } \multicolumn{1}{c|}{} & Density $\left(\mathrm{kg} / \mathrm{m}^{3}\right)$ & 1400 \\
\hline AISI 310 & 8000 & 3410 \\
\hline Tungsten & 19300 & 2870 \\
\hline Tungsten Carbide & 15600 & 3500 \\
\hline Niobium Carbide & 7600 & 3140 \\
\hline Titanium Carbide & 4900 & \\
\hline
\end{tabular}

TABLE II - Powder Sizes That Were Used in the Investigation

\begin{tabular}{|c|c|c|}
\hline Tungsten & & Avergge Size $0.5 \mu \mathrm{m}$ \\
\hline Tungsten & $-100 \mathrm{Mesh}$ & $<140 \mu \mathrm{m}$ \\
\hline Tungsten* & $-325+500$ Mesh & 25 to $44 \mu \mathrm{m}$ \\
\hline Tungsten* & $-200+325$ Mesh & 44 to $74 \mu \mathrm{m}$ \\
\hline Tungsten* & $-100+200$ Mesh & 74 to $140 \mu \mathrm{m}$ \\
\hline Tungsten* & $-60+100$ Mesh & 140 to $250 \mu \mathrm{m}$ \\
\hline Tungsten Carbide & & Average Size $1 \mu \mathrm{m}$ \\
\hline Niobium Carbide & & Average Size $2 \mu \mathrm{m}$ \\
\hline Titanium Carbide & & Average Size $0.5 \mu \mathrm{m}$ \\
\hline
\end{tabular}

*Sol-Gel Coated Tungsten Powder 
The glass coating was produced by mixing wet tungsten powder with tetraethyl orthosilicate (TEOS), $\mathrm{Si}\left(\mathrm{C}_{2} \mathrm{H}_{5} \mathrm{O}\right)_{4}$ which is in solution in ethanol. Molsture on the particulates reacts with TEOS and a glass coating is formed on the surface. With the wet particle, this process occurs at the surface of particle and to produce a coating. After the sol-gel coating process, the powder was drled in a furnace at $350^{\circ} \mathrm{C}$ temperature in argon gas atmosphere.

The powder cored welding filler wire was produced by starting with $200 \mathrm{~mm}$ long AISI 310 stainless steel tube with $25 \mathrm{~mm}$ outer diameter and $5.5 \mathrm{~mm}$ wall thickness. The tube dimensions result 17.5 vol-pct for the amount of the powder in fully packed tube, with a measured powder packing density of 50 vol. pct. After packing, the tubes were hot rolled to $5 \mathrm{~mm}$ diameter. After hot rolling the wire was cold rolled to the final diameter of $2.5 \mathrm{~mm}$. This practice produced approximately $20 \mathrm{~m}$ of final wire.

\section{Welding Procedure}

Gas tungsten arc welding (GTAW) of the test materials was done with a 3 mm diameter tungsten welding electrode and argon shielding gas using stralght current polarity. Weld deposits were produced as multibead welds with manual filler wire feed on $12.5 \mathrm{~mm}$ thick AISI 304 stainless steel plate with $90^{\circ}$ angle V-groove. Each weld deposit had three to four welded layers. Welding parameters of GTA welding was 200 A and 220 with manual control. Alternating and pulsation current modes were used in the GTA welding to study the effect of the welding current mode on the dispersion and recovery of particles in the weld pool.

Gas metal arc welding (GMAW) was done with an argon shielding gas. The welding current was straight polarity direct current to reduce the heat input to the electrode during tire welding procedure. The welding parameters of GMA welding was $300 \mathrm{~A}$ and $25 \mathrm{~V}$ with $58 \mathrm{~mm} / \mathrm{s}$ wire speed and $3.3 \mathrm{~mm} / \mathrm{s}$ travel speed. 


\section{Metallography}

Welded samples were prepared for metallographic investigation by grinding them with 100 to 600 grit sand paper and polishing with 6 and $1 \mu \mathrm{m}$ particle size diamond paste and $0.05 \mu \mathrm{m}$ particle size aluminum oxide. After polishing, the samples were examined with a light microscope and photographed. For area fraction measurements and size prediction of the second phase particles the Image analyzer LECO 2001 was used with a light microscope. Scanning electron microscope (SEM) and energy dispersive spectrometer (EDS) with MICROQ software were used to study the dissolution of the powder materials in the weld metal.

\subsubsection{Results and D1scussion}

Weld deposits for each powder type and for both gas metal arc and gas tungsten arc were analyzed. The results consist of micrographs from the weld deposits made with powder filled cored welding wire, chemical analyses of the weld metal using the energy dispersive spectrometer with a scanning electron microscope, and weld metal micro hardness profiles.

\section{Metal Matrix Particulate Composite Weld Deposits With Tungsten Powder}

Uncoated tungsten powders with $0.5 \mu \mathrm{m}$ and $100 \mathrm{Mesh}(<149 \mu \mathrm{m})$ particle sizes were initially used. In the experinents with uncoated tungsten powder In the core of welding filler, the recovery of the particulate second phase in the weld pool was found to be poor. A large fraction of the powder dissolved in the weld metal or slagged on the top of weld pool. This behavior was confirmed with the SEM/EDS measurements.

In GTA welding with - 100 Mesh tungsten powder filled cored wire a large fraction of the particulates clustered. These clusters were found in the bottom of the solidified weld pool and were 500 to $1500 \mu \mathrm{m}$ in diameter. The 
clusters of powder were smaller in the middle of the weld and did not exist in as large numbers as in the bottom. The amount of tungsten detected in the upper parts of the weld deposit was small and on large areas no tungsten particulates were detected at all.

Pulsed GTA and alternating current (AC) GTA welding procedures were used to study the effect of arc current mode on the powder dispersion in the weld pool. Ne1ther of the methods was found to reduce clustering with uncoated tungsten powder welding wire. During pulsed current and AC GTA welding the amount of tungsten that had dissolved in the matrix was measured to be higher than with direct current GTA welding. The remaining powder agglomerates that were not dissolved, were mostly found in the bottom of the weld pool.

A large amount of the tungsten powder dissolved in the stainless steel matrix during the gas metal welding procedure of $0.5 \mu \mathrm{m}$ and $-100 \mathrm{Mesh}$ powder filler wires. The features in the microstructure are similar to those in GTA welded samples. Most of the powder exists in the bottom of the weld deposit and formed large agglomerates, while the middle areas have few particulates and the top areas none. Weld metal solidification cracking was observed at the lower areas of the weld deposits with clustered powder in both GTA and GMA welded deposits.

\section{Glass Coated Tungsten Powder}

The experiments with uncoated tungsten powder showed a low recovery of particulates in the weld deposit because of slagging and dissolving losses of the particulates. Glass coating was produced on the particulates to minimize this behavior and to enhance the amount of the second phase particles produced in the weld metal. The coating forms a physical barrier on the particles reducing its dissolution rate in the matrix metal. Also, powder size distribution was varied in this part to study the effect of particle size on 
the solidification behavior and recovery and dispersion of particulates in the weld pool. The welding wires, which were manufactured with the coated powder, were welded using both the GTA and the GMA welding processes.

In gas tungsten arc welded deposits the recovery of coated tungsten particles in the weld pool was observed to be better for all particle sizes than with using uncoated tungsten powder with $0.5 \mu \mathrm{m}$ and $100 \mathrm{Mesh}$ powder sizes. The powder particles were found to form clusters with the two smaller size categories, $-325+500$ and $-200+325$ Mesh powder sizes, which is illustrated in Figure 12. In these weld deposits the agglomerated powder was located mainly in the bottom of the weld. The amount of tungsten particles in the upper parts of the weld was small. In the middle parts of the weld deposit the particles showed some dispersion behavior. In some areas the clustered powder particles had some matrix metal in between them. This behavior was observed in the middle parts of the weld deposit. Cracking can be observed in the areas with powder clusters.

The gas tungsten arc weld deposits with flller wires that were produced in this part of the investigation have two larger particle sizes, $-200+100$ and $-60+100$ Mesh. These coated tungsten powders showed acceptable dispersion behavior of the second phase in the stainless steel matrix. The distribution of the particles in the weld metal is uniform and no clustering behavior can be seen. The amount of the second phase is larger in the bottom of the weld compared to the middle and upper parts. But unlthe the smaller particle size weld deposits, these materlals have particles in the upper parts of the weld as well. The matrix metal fills the interparticle areas uniformly. No cracking was observed in the weld metal with particulate second phase with these powder size categories.

The weld deposits that were produceo with gas metal arc welding process using coated tungsten powder filled cored wire showed the same type of results 

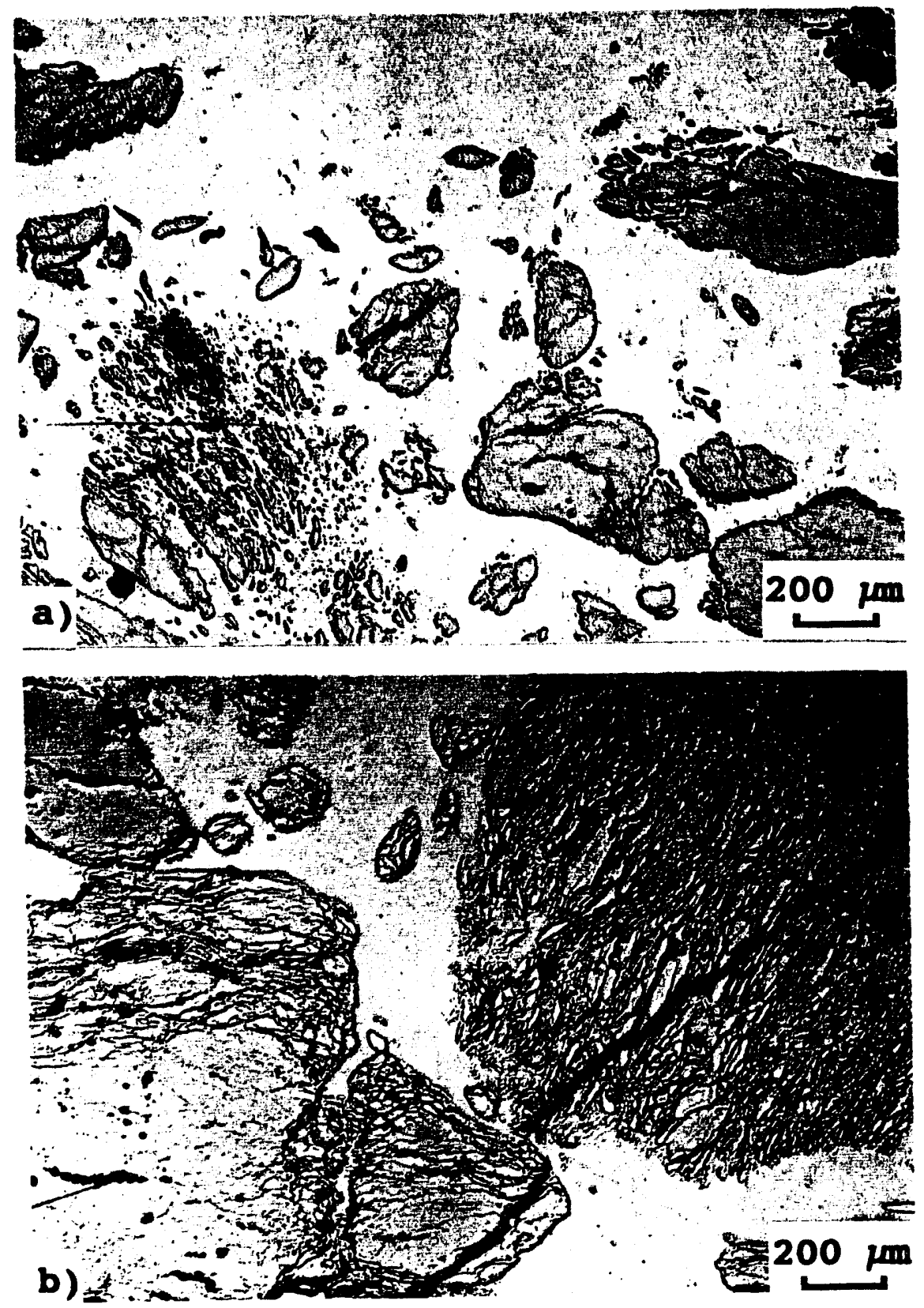

Figure 12. The microstructure of glass coated $-325+500$ mesh tungsten powder cored filler wire gas tungsten arc welds. (a) mid weld, (b) lower weld. 
as the GTA welded samples. The two smaller powder sizes tend to agglomerate and sink in the bottom of the weld deposit and cause cracking in the clustered areas. The two larger powder sizes distributed better and the weld metal did not have clustering or cracking problem. The recovery of the particles in the weld pool during GMA welding was found to be smaller than with GTA welded samples. The amount of the second phase in the weld pool is smaller with the same powder size when compared to the GTA welded samples.

\section{Composite Weld Deposits with Tungsten Carbide Pouder}

Tungsten carbide was selected for a powder material to represent a potential second phase material with density between the densities of tungsten and the stainless steel matrix. The experiments with tungsten carbide powder filled cored wire with both gas metal arc and gas tungsten arc welding procedures showed poor recovery of second phase particulates in the weld pool. A large fraction of the powder transferred to the weld pool dissociated and dissolved in the matrix, the rest of the powder formed large clusters located in the bottom of the weld.

The powder agglomerates that were found in the gas tungsten arc weld metal were located in the bottom of the pool. The upper parts of the pool had areas where the tungsten carbide powder had dissociated and dissolved in the matrix forming intermetallic phases with iron and chromium. Very small amount of or no tungsten carbide particulates can be found in upper parts of the weld deposit.

The features with gas metal arc welded deposit looked similar to those of the GTA welded deposit. The powder formed large agglomerates located in the weld root area, most of the upper parts did not have any particulates, and intermetallic phase formation was detected in large quantities. The phase 
appeared in the Interdendritic areas and is an eutectic solidification product according to the scanning electron microscopy investigation.

Solldiflcation cracking was observed in the solidified weld metal in the areas with powder agglomerates. The cracks were detected in both GMA and GTA welded deposits. The dissolving rate of tungsten carbide powder in the matrix was found to be highest when compared to the other powder materials used.

\section{Composite Weld Deposits with Nlobium Carbide Powder}

Niobium carbide has a density just below that of the stainless steel. Nioblum carbide was used to study how powder particles behave in the solidification structure of a weid deposit when the densities of the materials are close to each other.

From the microstructures of gas tungsten arc and gas metal arc welds made with nioblum carbide powder fllled welding wire it can be seen that the niobium carbide powder tends to form large agglomerates which sink in the lower parts of the weld pool. The largest of the powder clusters were detected to be one to two $\mathrm{mm}$ size in diameter. The upper parts of the weld had few particles. The amount of the powder that have dissolved in the matrix was measured to be small. The dissolving rate was smaller than that with tungsten and tungsten carbide powders.

The gas metal arc weld microstructures had acceptable particle dispersions. The niobium carbide particles have been dispersed uniformly in different parts of the weld pool. There was not a big difference in the distribution of particulates between the upper and lower part of the pool. However, some clustering of the powder was detected, but the agglomerates were smaller in size than those in GTA welded niobium carbide filled wire and the fraction of them on the weld metal was smaller. The size of the powder 
clusters ranged less than one $\mathrm{mm}$ in diameter. No solidification cracking was observed in the weld metal produced with nioblum carbide filled wire.

\section{Composite Weld Deposits with Titanium Carbide Powder}

Titanium carbide had the lowest density of the test material powders, being $0.0049 \mathrm{~g} / \mathrm{mm}^{3}$. Titanium carblde was selected to study how solidification of a weld deposit take place with low density powder particles.

The microstructure of the weld metal produced with titanium carbide powder filled wire with gas tungsten and gas metal arc welding procedures can be seen in Figures 13 and 14 . The powder dispersion is uniform and only minor clustering of powder can be notifled. The dissolution rate of the powder in the matrix is low and acceptable.

The particle dispersion in gas tungsten arc weld pool is uniform as can be seen in Figure 13. No differences between upper and lower areas of the weld pool were detected. Some clustering and agglomerate formation had taken place, but this occurrence was not a trend with this powder-welding procedure combination. Particles were pushed into interdendritic areas during solidification so that the dendrite arms can be observed in the solidification structure. This observation was assumed to be due to the low density of the powder with small radius and matrix and low solidification velocity. In equation (36) it was presented that the interface velocity during the solidification has a critical value of $V_{c r}$. Below this velocity value the particles are pushed into last solidifying areas.

The gas metal arc weld metal microstructure appeared similar to the GTA weld metal. The microstructure is presented in Figure 14. Powder dispersion is uniform on all parts of the weld deposit. Some powder agglomerates could be detected, however they are fewer than experienced in the GTA weld metal. The particles were not in the solidification structure in interdendritic areas 

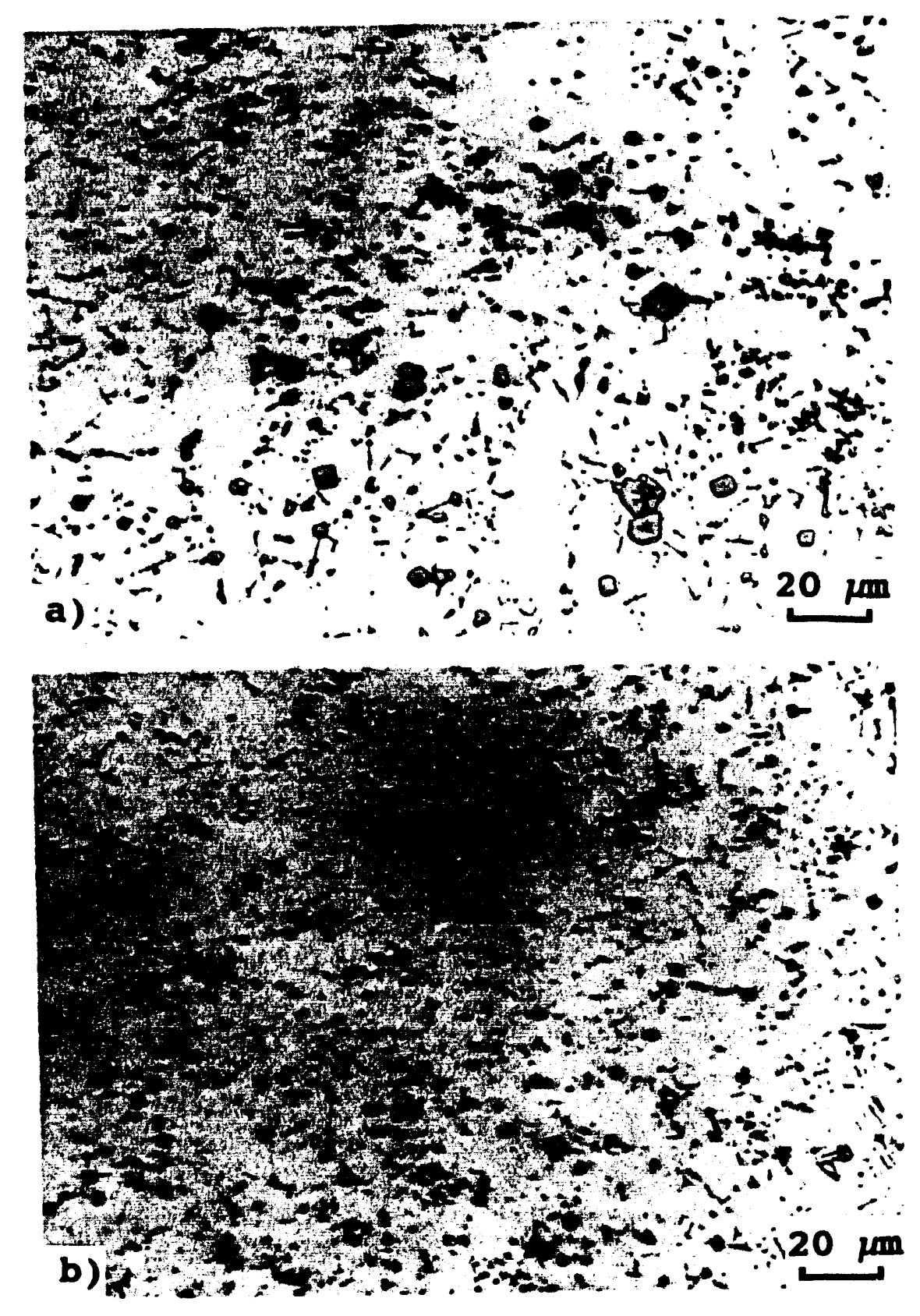

Figure 13. The microstructure of a $1.0 \mu \mathrm{m}$ titanium carbide powder cored filler wire gas tungsten arc welds. (a) mid weld, (b) lower weld. 

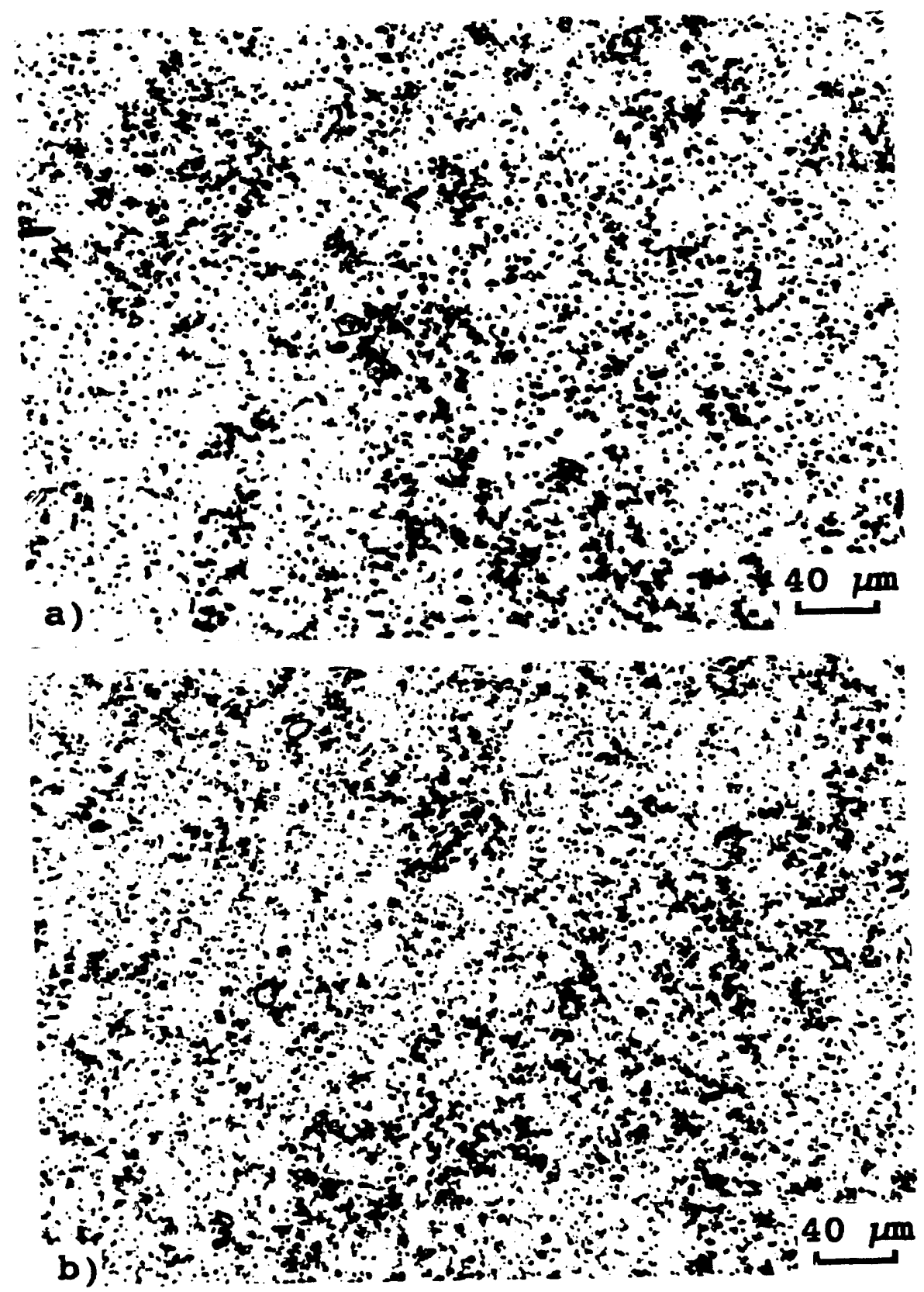

Figure 14. The microstructure of $1.0 \mu \mathrm{m}$ titanium carbide powder cored filler wire gas metal arc welds. (a) mid weld, (b) lower weld. 
as they were in GTA weld weld deposits. This behavior was assumed to occur because of the higher cooling rate of the weld pool.

The dissolution rate of titanium carbide in the matrix was the lowest among the test materials that were used. The chemical analyses determined for different parts of the weld deposit are similar to those resulting from niobium carbide powder filled cored wire. No reaction zone around the TIC particles was detected. Cracking did not occur in the weld pool produced with titanium carbide powder filled wire.

\subsubsection{Movement of the Particles in the Liquid Weld Metal}

The flow of particulates in weld pool was studied using equations (36), (37) and (38). In the calculation $0.006 \mathrm{~kg} / \mathrm{ms}$ was used for the viscosity of the liquid metal $(\eta)(59)$ and for the welding parameters that were used, 0.15 $\mathrm{m} / \mathrm{s}$ was given as a value for the weld pool velocity $\left(v_{w p}\right)$ by Woods and Millner (60). The results can be seen in Figure 15. The data points of the investigated powder materials are also marked in the figure.

The calculated results showed that the suspension velocity of the liquid $\left(v_{1}\right)$ for the particles in the weld pool is lower than the weld pool velocity for every powder size category that was used in this investigation. The friction force that was calculated using weld pool velocity $0.15 \mathrm{~m} / \mathrm{s}$, is the dominating force for each powder size. This comparison suggests that the particles should disperse because the friction force overcomes other existing forces.

In Figure 15 the calculated flow velocities for particle suspension with different particle radius values and density values using weld pool velocity $\left(v_{w p}=0.15 \mathrm{~m} / \mathrm{s}\right)$ have been plotted. The dotted curve in the figure represents the density and radius values for particle suspension to exist with used weld pool velocity. The particles that are losated to the right of the curve have 


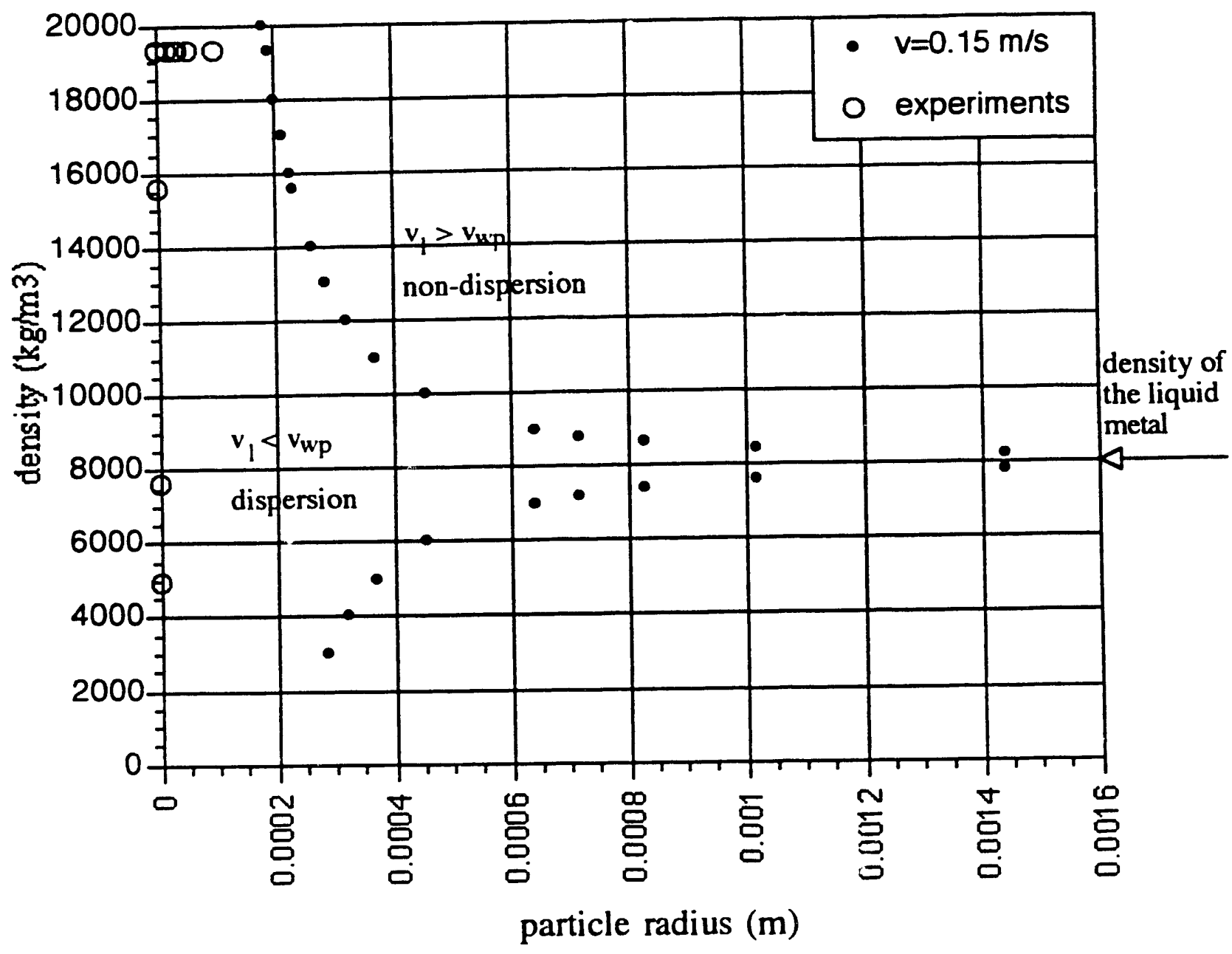

Figure 15. The particle density plotted as a function of radius for particle dispersing with $v_{\mathrm{wp}}=0.15 \mathrm{~m} / \mathrm{s}$. (0) indicate the data points used in the investigation. $v_{w p}$ is the weld pool velocity and $v_{1}$ is the liquid velocity for particle suspension. 
greater liquid velocity for particle suspension than the weld pool velocity. Based on the concept of this model these particles would not disperse. All of the investigated powder materials are located to the left of the particle suspension velocity curve. This observation suggests that these particulates should disperse in the weld pool because the weld pool velocity is greater than the liquid velocity for particle suspension.

However, non-dispersion behavior was observed with some of the powder materials having a low fluid velocity for particle suspension. This behavior was assumed to occur because the model does not take into account the powder interactions and because the flow conditions in the weld pool are more complicated than assumed in the model. Particle interactions are more probable with small powder sizes because the mean particle separation becomes smaller when the powder size is reduced with a constant powder volume fraction. Also, when powder particles interacted and agglomerated the effective particle size is increased. When the particle size increases the weld pool velocity for particle dispersion increases. The liquid velocities for particle suspension were calculated using average particle size values. The particle size distribution can cause difference between predicted and actual particle dispersion situations.

The predicted liquid flow conditions are presented schematically in Figure 16. The hatched area in the bottom of the weld pool in the figure illustrates an area where the flow velocity can have low value or be zero. The low velocity area exists in the pool because of these areas are trapped by streams. If the weld pool velocity is low enough it can be below the liquid velocity of particle suspension for the material that is been used. This condition supports the interaction between powder particles and causes non-dispersion of the particles and can lead to formation of agglomerates. In the area with low flow velocity the probability for particle interaction and 


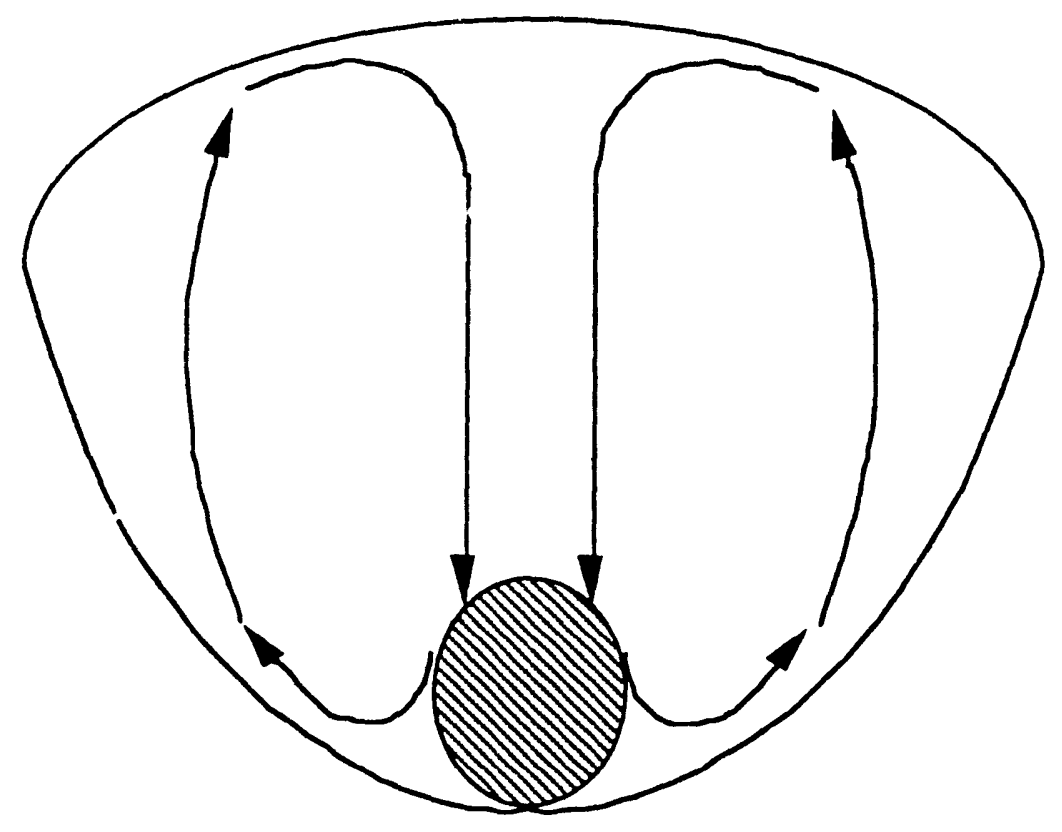

Figure 16. A schematic presentation of the weld pool flow streams. Hatched area remarks the area with $v_{1} \approx 0 \mathrm{~m} / \mathrm{s}$. 
agglomeration is higher. The powder clusters which were found in the weld deposits produced with small particle size tungsten and tungsten carbide powders were located mainly in lower weld pool areas.

In Figure 17 the effect of low weld pool velocity on the liquid velocity for particle suspension has been illustrated. The density values for particle suspension as a function of radius has been calculated with a $v_{w p}$ value of $1.5 * 10^{-7} \mathrm{~m} / \mathrm{s}$. In the figure it can be seen that if the weld pool velocity is $1.5 * 10^{-7} \mathrm{~m} / \mathrm{s}$ only two of the experimental powders with densities 4900 and 7600 $\mathrm{kg} / \mathrm{m}^{3}$ would disperse.

\subsubsection{Average Size and Area Fractions of Second Phase in the Weld Deposit}

The mean radius ( $r$ ) and the mean distance between particles ( $\lambda$ ) calculated from the image analyzer measurements are shown in Figures 18 and 19. The measurements show that titanium carbide produces the smallest average second phase particle radius to the weld deposit. This can be seen in Figure 18. Niobium carbide has the second smallest average particle radius. Measurements for weld deposits produced with wire filled with different tungsten powder sizes showed that the two initially largest size powders produce the smallest second phase particle radius. This behavior occurs because of the particles in weld deposits produced with a wire filled with small particle size powder tend to form large agglomerates in the structure. The formation of these agglomerates increases the effective particle radius.

The largest area fraction of powder was measured with $-60+100$ Mesh coated tungsten powder filled wire weld deposit. The lowest area fractions were observed in -100 Mesh uncoated and $-325+500$ Mesh coated powder filled wire welded deposits. 


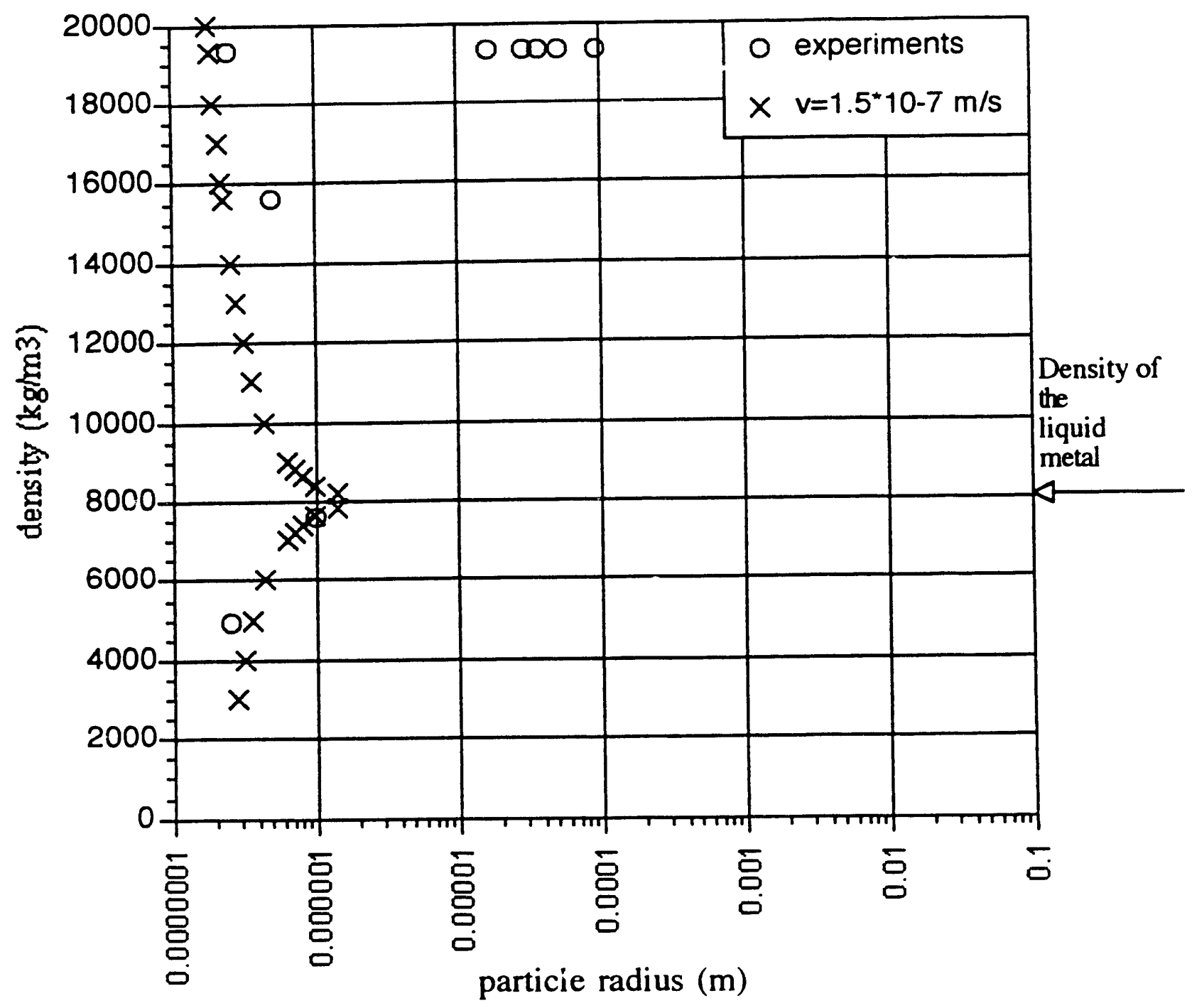

Figure 17. Particle density plotted as a function of radius for particles to suspend with vwp $=0.15 \mathrm{~m} / \mathrm{s}$ and $v_{\mathrm{wp}}=1.5 * 10^{-7} \mathrm{~m} / \mathrm{s}$. (O) Indicate the data point used in the investigation. 


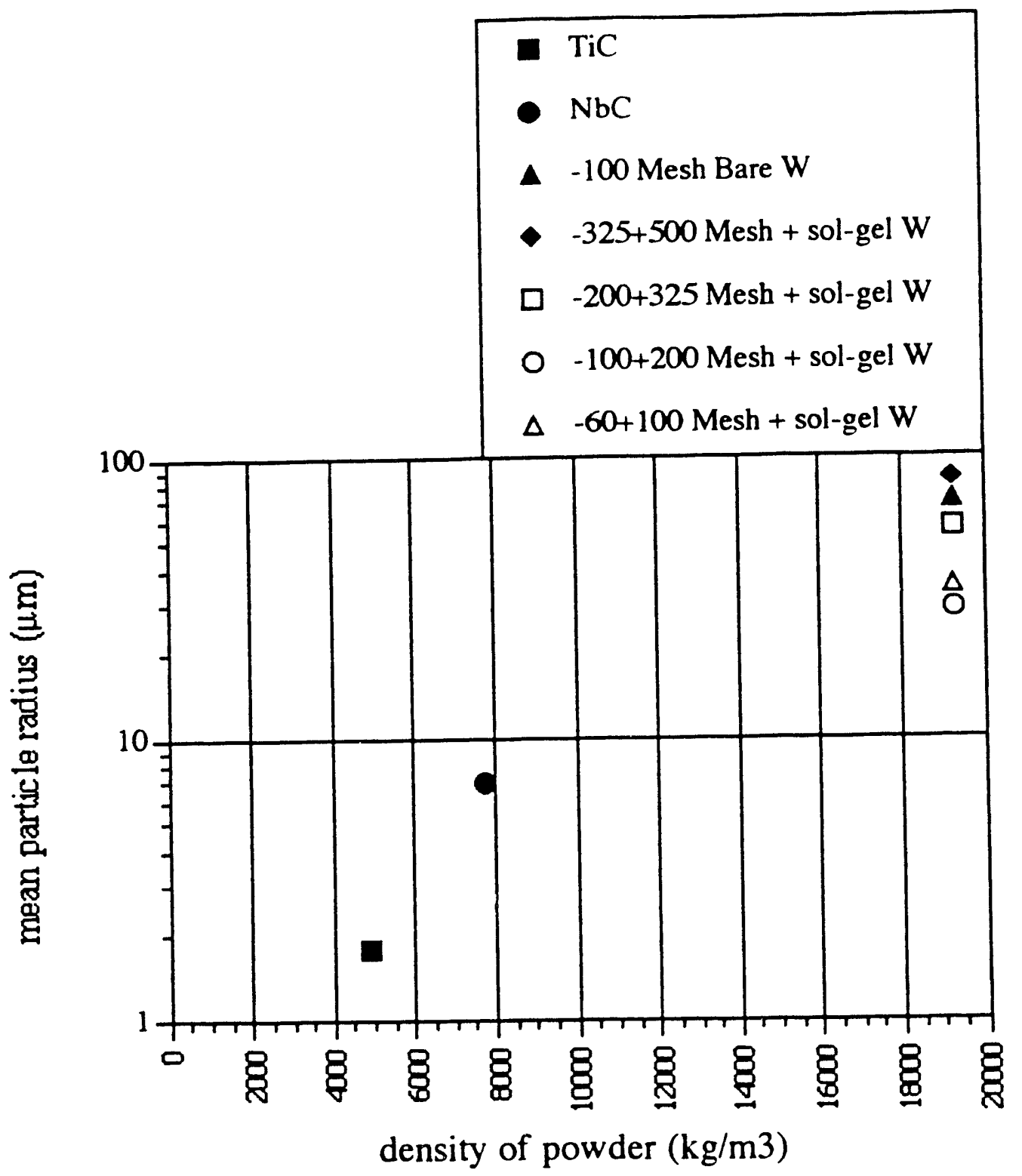

Figure 18. The mean particle radius ( $r$ ) produced with different types of powder. 


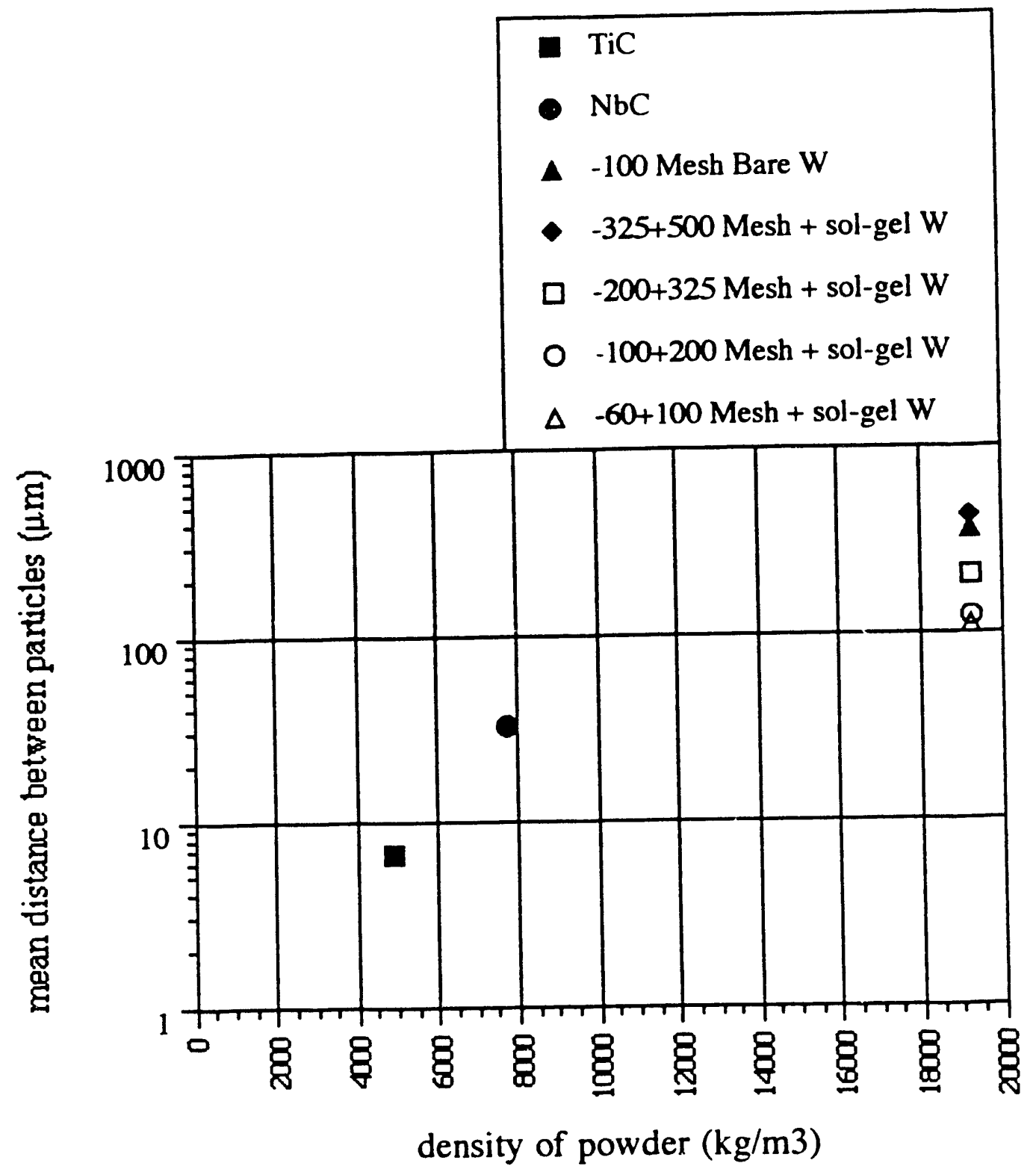

Figure 19. Mean distance between particles $(\lambda)$ with different powder materials. 


\subsubsection{Conceptional Design Criteria of the Composite Weld Deposits with Desired Properties}

The design of particulate composite weld deposits must consider the criteria for enhanced creep resistance due to the particle reinforcement of the alloy and the effect of powder size distribution on the achieved microstructure. The particle radius and mean free path for particle reinforcement is plotted as region for particle reinforcement in Figure 20. In the same figure the mean free path values are plotted as a function of particle radius from the image analyzer results. The region which is marked as dispersion of particles in Figure 20 is based on the observations in the experiments with different powder size distributions. The particle radius is a linear function of the mean free path between particles only with one particle volume fraction value. The optimum design criteria would be the overlapping area of the regions in Figure 20. In this area both the particle strengthening and the right processing conditions would be expected to exist.

\subsubsection{Summary: Metal Matrix Composite Weld Deposits}

This research has demonstrated that particulate metal matrix composite weld deposits can be made and that the particles can be transferred through the arc into the weld pool. The particle dispersions can be controlled with proper selection of powder. The criterion for optimum powder material include particle size, type, density and composition. Powder type and composition are important factors which affect the behavior of the second phase particles in the weld metal solidification structure. The powder should be chosen so that the expected reactions with the matrix material will be minimized. Coatings can be used to slow down or prevent reaction between particle and matrix. Coatings will also decrease powder dissolution rates into the matrix. 


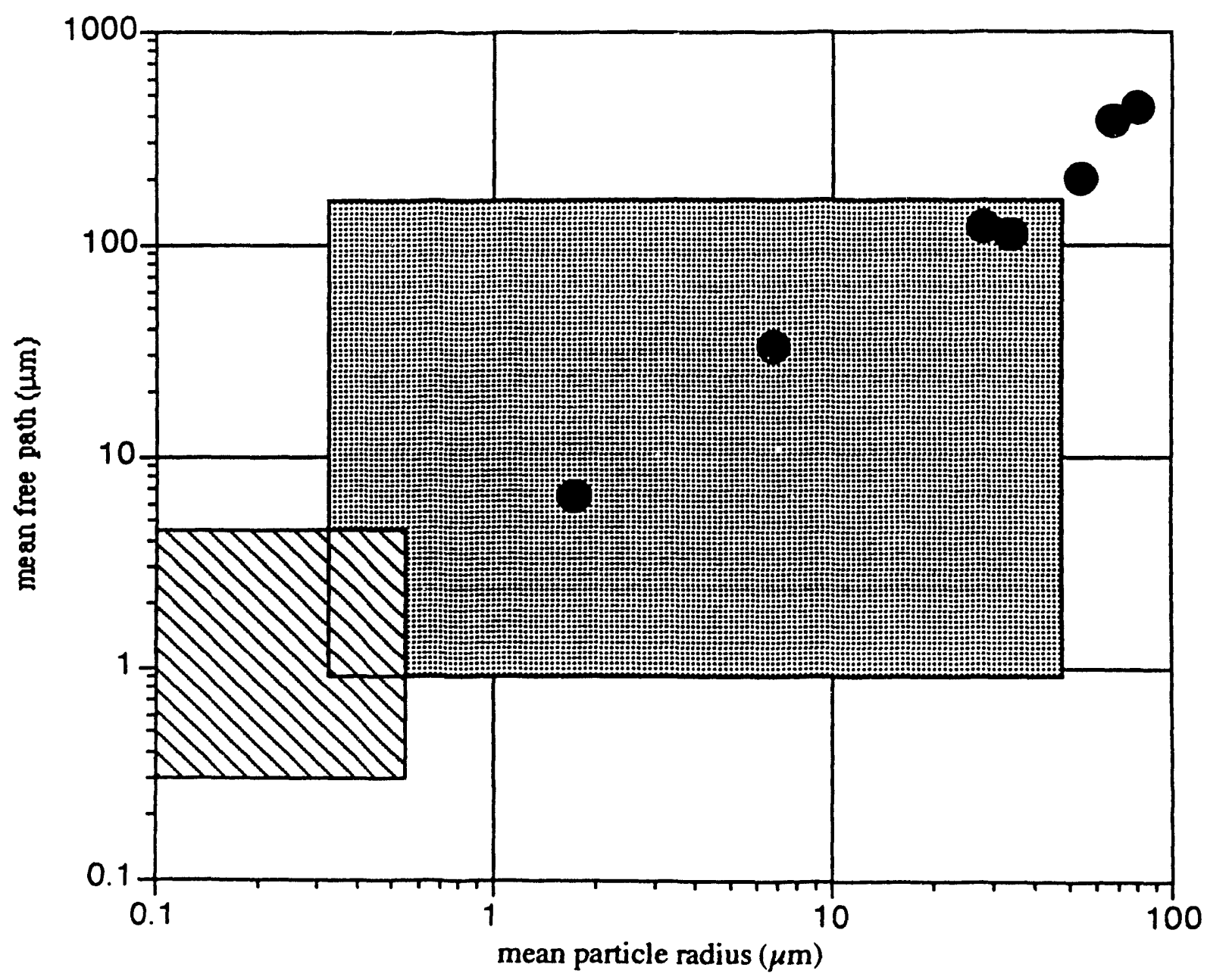
experiments $\quad \begin{aligned} & \text { region for particle } \\ & \text { dispersion in the }\end{aligned}$ region for higher creep resistance due to the wela pool particle reinforcement

Figure 20. Conceptual design criteria for the particulate composite weld deposit. 
Particle size is an important factor. This investigation has shown that particle size will influence the distribution of the particles in the weld pool together with the density of the powder. Selection of welding process and welding variables will influence particle distribution.

The efficlency of transferring particles depends on the composition and size of the powder. Transfer loss has been observed to be higher with smaller particle size with the same powder material.

The composite consumable can be made with the same methods as flux cored welding consumables. In this study cold rolling was found preferable for manufacturing the composite wire to drawing.

As a proposed future improvement for making particulate metal matrix composite weld deposits it is suggested that a different method should be used to produce the powder filled cored welding wire. It was belleved that the manufacturing method that was used in this work may increase the tendency for the powder clustering during the welding procedure. 
1. D.L. Olson, S. Liu, and G.R. Edwards, "Role of Solldiflcation on HSLA Steel Weld Metal Chemistry", Weldablilty of Materlals, ed. by R.A. Patterson and K.W. Mahin, PP. 183-189, ASM, Materlals Park, OH (1990).

2. C.B. Dallam, S. Liu, and D.L. 01son, "Flux Composition Dependence of Microstructure and Toughness of Submerged Arc HSLA Weldments", Welding Journal, $\underline{65}$ (5), pp. 140s (1985).

3. J.E. Indacochea, M. Blander, N. Christensen, and D.L. O1son, "Chemical Reactions with FeO-MnO-S1O 2 Fluxes", Met. Trans., 16B, PP. 237 (1985).

4. S. Liu and D.L. 01son, "The Role of Inclusions in Controlling HSLA Steel Weld Metal Microstructures", Welding Journal, 65 (6), pp. 139s (1986).

5. S. Liu and D.L. Olson, "The Inclusion Chemical Composition on Weld Metal Microstructure", Journal of Material.s Engineering, 9, pp. 237 (1987).

6. O. Grong and D.K. Matlock, "Microstructural Development in Mild and Low Alloy Steel Weld Metals", Int. Met. Rev., 31, pp. 27 (1986).

7. D.W. Oh, D.L. Olson, and R.H. Frost, "The Influence of Boron and Titanium on Low Carbon Microalloyed Steel Weld Metals", Welding Journal, 69 (4). pp. 151s (1990).

8. C.W. Ramsay, D.L. Olson, and D.K. Matlock, "The Influence of Inclusions on the Microstructure and Properties of High Strength Steel Weld Metal", in Conf. Proc. on "Recent Trends in Welding Research", Gatlinburg, TN, ASM, Pp. 763 (1990).

9 D.L. 0lson, S. Liu, and G.R. Edwards, "Role of Solidification on HSLA Steel Weld Metal Chemistry", Weldability of Materials, ed. by R. A. Patterson and K. W. Mahin, pp.183-189, ASM, Materials Park, OH, (1990).

10. A.L. Schaeffler, Metal Progress 56, 680, (1949).

11. K.W. Andrews, JISI 203, 721, (1965).

12. G.H. Eichelmann and F.C. Hul1, Trans ASM 45, 77, (1953).

13. J.A. Self, D.K. Matlock and D.L. Olson, Welding Journal 63 (9), 282s, (1984).

14. J.A. Self, B.F. Carpenter, D.L. Olson and D.K. Matlock, "Phase Transformation and Alloy Stability in Fe-Mn-Ni-Cr-Al Weld Metal", Alternate Alloying for Environmental Resistance, ed. by G. R. Smolik and S. K. Banerji, pp.37-45, AIME, Warrenville, PA, (1987).

15. B. Strauss and E. Maurer, Kruppsche Monatshefte 1, 129, (1920).

16. T. Takalo, N. Suutala, and T. Moisio, Met. Trans. 10a, 1173-81, (1979).

17. N. Suutala, Met. Trans. 13a, 2121-30, (1982). 
18. M.J. Cleslak, G.A. Knorovsky, T.J. Headley and A.D. Romig, Jr., Met. Trans. 17a, 2107-2115, (1986).

19. B.F. Carpenter, D.L. Olson, D.K. Matlock and M.J. Cleslak, to be published in Mat. Sc1. and Eng., (1991).

20. B.F. Carpenter, "New Phacomp Prediction of the Phase Stability of Fe-AlCr-Mn-N1 Weld Metals", Thesis T-3557, Colorado School of Mines, Golden, Colorado, (1989).

21. J.S. Ogborn, "An Examination of the Solidification Behavior and Microstructural Evolution in Nickel Base Alloys", Thes is T-3625, Colorado School of Mines, Golden, Colorado, (1988).

22. M. Morinaga, N. Yakawa, H. Adachi and H. Ezaki, Proceedings of Superalloys, Pp.523-532, (1984).

23. M. MorInaga, N. Yukawa and H. Adach1, J. Phys. Soc. Jap. 53 (2), 653$663,(1984)$.

24. L.R. Woodyatt, C.T. Sims and H.J. Beattie, Trans TMS-AIME 236 (4), 519527, (1968).

25. J.W. Cahn and J.E. Hilliard, J. Chem. Phys. 28 (2), 258-267, (1958).

26. C.R. Johnson and J.D. Grimsley, Nasa Technical Note TN D - 4673, Washington, DC, July 1-7 (1968).

27. W.A. Bapslack, III, J.C. Lippold, and W.F. Savage, Weld. J. 58 (6), Pp. $168 \mathrm{~s}-176 \mathrm{~s}$, June (1979).

28. G.R. Berry, Jr., Thesis No. T-3640, Colorado School of Mines (1989).

29. I.D. Cho1, D.K. Matlock, and D.L. Olson, Scripta Met., 22, pp. 1563 (1988).

30. J.M. Barsom and S.T. Rolfe, "Fracture and Fatigue Control in Structures - Application of Fracture Mechanic", Second Edition, Prentice Hall, Inc., New Jersey (1987).

31. E.A. Guggenheim, Trans. Faraday Soc., 41, pp. 150-156 (1945).

32. K.S. Vecchio, R.W. Hertzberg, J. Mat. Sc1., 23, pp. 2220-2224 (1988).

33. G.A. Miller, D.H. Avery, and W.A. Backofen, Trans. TMS-AIME, 236, Pp. 1667-1672 (1966).

34. J.C. Grosskreutz, Met. Trans., 3 (5), Pp. 1255-1262 (1972).

35. J.P. Hirth, Metal1. Trans., i (9), pp. 2367-2374 (1970).

36. I.D. Choi, "Influence of Compositon Gradients on Weld Metal Creep Behavior: An Analysis Based on Laminate Composites", Ph.D. Thesis No. 3699, Colorado School of Mines, Golden, Colorado, 1989. 
37. W.S. Gibbs, S.H. Wang, D.K. Matlock, and D.L. O1son, "High Temperature Impression Creep Testing of Weldments", Welding Journal, vol. 64, No. 6, 1985 , pp. 153s-158s.

38. I.D. Choi, D.K. Matlock, and D.L. Olson, "The Influence of Composition Gradients on Tensile Properties of Weld Metal", Scripta Metallurgica, vol. 22, 1988, pp. 1563-1568.

39. I.D. Chol, D.K. Matlock, and D.L. Olson, "Influence of Composition Gradients on Weld Metal Creep Behavior: An Analysis Based on Laminate Composites", Recent Trends in Welding Sclence and Technology, ed. by S.A. David and J.M. Vitek, ASM, Metals Park, Ohio, 1990, pp. 787-791.

40. I.D. Choi, D.R. Matlock, and D.L. O1son, "Creep Behavior of Nickel-Copper Laminate Composites with Controlled Composition Gradients", Metallurgical Transactions A, vol. 21A, 1990, pp. 2513-2520.

41. M.A. Lisin, I.D. Choi, D.K. Matlock, and D.L. Olson, "A Composite Modeling Analysis of Impression Creep Testing on Heterogeneous Materials", Welding Journal, Research Supplement, vol. 69, no. 4, 1990, pp. $159-\mathrm{s}$ to $165-\mathrm{s}$.

42. R.W. Bazuffi, Acta Metallurgica, vol. 2, 1954, p. 194.

43. F. Seitz, Acta Ketallurgica, vol. 1, 1953, p. 81

44. R.G. Thomas, "The Effect of $\delta$-Ferrite on the Creep Rupture Properties of Austenitic Weld Metals", Welding J., 57, pp. 81s-86s (1978).

45. R.W. Evans and B. Wilshire, Creep of Metals and Alloys, The Institute of Metals, London, England (1985).

46. Z.G. Zhu and G.J. Weng, "Creep Deformation of Particle-Strengthened Metal Matrix Composites", J. Engineering Materials and Technology, 111, pp. 99-105 (1989).

47. P.J. Threadgill and B. Wilshire, "The Effect of Particle Size and Spacing on Creep of Two-Phase Copper-Cobalt Alloys", Metal. Sci., $\underline{8}$, pp. $117-124$ (1974).

48. J. Peterseim and G. Sauthoff, "Analysis of the Dependence of Creep on Stress, Temperature and on the Distribution of Small Particles in Fe-CrAlloys", Deformation of Multi Phase Particle Containing Materials, Riso National Laboratory, Roskilde, Denmark (1983).

49. J 3. Bilde-Sorensen, "Creep in Particle-Containing Materials", Deformation of Multi Phase ind Particle Containing Materials, Riso National Laboratory, Roskilde, Denmark (1983).

50. D.M. Stefanescu, B.K. Dhindaw, S.A. Kacar and A. Moitra, "Behavior of Ceramic Particles at the Solid-Liquid Metal Interface in Metal Composites", Met. Trans., 19A, pp. 2847-2855 (1988). 
51. D.R. Uhlmann, B. Chalmers and K.A. Jackson, "Interaction Between Particles and a Solid-Liquid Interface", J. Applied Physics, 25, pp. 2986-2992 (1965).

52. D. Azbel and A.I. Liapis, "Motion of Solid Particles in a Liquid Medium", Handbook of Fluids in Motion, ed. N.P. Cheremisinoff and R. Gupta, Ch. 34, Ann Arbor Science Publishers, Ann Axbor, Michigan (1982).

53. L. Lajoye and $M$. Suery, "Modeling of Particle Segregation During Casting of A1-Matrix Composites", Cast Reinforced Metal Composites, ASM, Materials Park, Ohio (1988).

54. R. Warren, C.-H. Andersson and L.O. Larsson, "The Effects of Composition on the Microstructure and Properties of W-Wire Reinforced Fe-Alloys", Verbundewerkstoffe, Deutsche Gesellschaft fur Metallkunde, Oberursel, FRG , 1981).

55. V.R. Narva, N.S. Loshkareva, M.N. Kryanina and E.P. Shurenkov, "Laser Treatment of Sintered TiC-Steel Alloys", Met. Sci. Heat Treat. (USSR), 29, pp. 792-795 (1987).

56. A.M. Ritter, M.R. Jackson and R.N. Wright, "Fracture of Steel/Carbide Particulate Composites", Advances in Fracture Research, Pergamon Press, Oxford, England (1989).

57. S. Ramalingam and P.K. Wright, "Abrasive Wear in Machining: Experiments with Materials of Controlled Microstructure", J. Eng. Materials and Tech., 103, pp. 151-156 (1981).

58. P.S. Dunn, C.A. Natalie, and D.L. 01son, "Sol-Gel Fluxes for Cored Welding Consumables", J. Materials for Energy Systems, 8 (9), pp. 176184 (1986).

59. G.M. Orper and J. Szekely, "A Comprehensive Representation of Transient Weld Pool Development in Spot Welding Operations", Met. Trans., 18A, pp. $1325-1332$ (1987).

60. R.A. Woods and D.R. Milner, "Motion in the Weld Pool in Arc Welding", Welding J., 18, p.). 163s-173s (1971). 


\subsection{COLLABORATIVE WORK}

The Colorado School of Mines is performing cooperative research with the following federal facilities: (a) Sandia National Laboratory (Albuquerque, New Mexico), on phase stability calculations and analysis; (b) Los Alamos National Laboratory, on solid state bonding research; (c) Oak Ridge National Laboratory, on aluminide welding research and special materials characterization; (d) Rocky Flats Plant, on weld metal cracking and brazing research; (e) Solar Energy Research Institute, on special electron microscopy analysis. CSM also hosted the BES-Welding Program Review, October, 1991. 


\subsection{ACCOMPLISHMENTS DURING THIS CONTRACT YEAR}

\subsection{Summary of Accomplishments}

1. Laminate composites of pure nickel and $\mathrm{Ni}-\mathrm{Cu}$ solid solution alloys have been fabricated and shown to exhibit predicted properties with respect to porosity formation during high temperature exposure.

2. Creep data in laminate composites have been obtained as a function of stress and temperature and have been shown to depend on the dynamic concentration gradients which develop during creep.

3. Techniques for evaluating the fine interlayer microstructures in laminate composites have been developed and the resulting dislocation structures in crept samples have been evaluated in a study performed jointly with the transmission electron microscopy group at the Solar Energy Research Institute.

4. The basics of an FEM analysis of creep in laminate composites have been identified, and an initial analysis with NIKE2D has been completed. An analysis with a viscoplasticity FEM model has been initiated.

5. The concept of using metal matrix composite weld deposits as a method to design advanced weldments was demonstrated. The physical conditions to achieve a high volume fraction of second phase with a proper particle distribution were identified. Preliminary modeling of the influence of fluid flow and solidification during welding of the MMC weld deposit was achieved.

6. Fatigue cracks propagate through regions of steep compositional gradients in cored material. Fatigue cracks have been characterized in both directionally solidified $\mathrm{Cu}-\mathrm{Ni}$ coatings and $\mathrm{Cu}-\mathrm{Ni}$ single crystals. 


\subsection{Publications: Accepted and Published}

1. D.I. Olson and D.K. Matlock, "Compositional Gradient Effects on Weldment Properties", Proc. ASM "Weldability of Materlals Symposium", Detroit, Michigan, October 6-12, pp. 49-56, ASM, Materlals Park, OH, (1990).

2. G. Berry, D.L. O1son, and D.K. Matlock, "Compositional Gradient Effects on Stress Corrosion Cracking Behavior of Weld Metal", Mat. Sci. and Engr. (1991), in press.

J

3. D.L. Olson and D.K. Matlock, "Weld Metal Phase Stability", Proc. AIMETMS Symp. on The Metal Science of Joining, TMS-AIME, October 20-24, Cincinnati, OH (1991), in press.

4. A. Wahid, D.L. Olson, D.K. Matlock, and J.J. Kelly, "Role of Compositional Gradients in Environmentally Promoted Weld Cracking", Proc. of ASM "Heat Resistant Materials Conference", PP. 447-452, ASM, Materials Park, OH (1991).

5. B.F. Carpenter, D.L. O1son, D.K. Matlock, and M.J. Cieslak, "Phase Stability of Fe-Al-Cr-Ni Weld Metal", Materials Science and Engineering, 1991 , in press.

6. Clay Lawrence Taylor "The Effect of Weldability of Alloy JBK-75 with Various Filler Metal Wire Additions", M.S. Thesis, \#T-4060, Colorado School of Mines, Golden, Colorado (1991).

7. Esa I. Kivineva (1991), "Particulate Metal Matrix Composites as a Weld Deposit", M.S. Thesis, \#T-4108, Colorado School of Mines, Golden, Colorado ( $(\bar{g} \bar{g} I)$. 


\subsection{Manuscripts: Submitted and in Preparation}

1. M. Holt, D.L. Olson, and C.E. Cross, "Interfacial Tension Driven Fluid Flow Model for Hot Cracking", to be submitted to Scripta Met. (1992).

2. T.A. Slewert, C.N. McCowan, and D.L. Olson, "Ferrite Number Prediction for Stainless Steel Welds", to be published in Ferrous Alloy Weldments, Trans. Tech. Publ. (1992).

3. A. Wahid, D.L. 01son, and D.K. Matlock, "Corrosion of Weldments: The Influence of Non-Uniform Compositional Conditions", (1991).

4. C.L. Taylor and D.L. Olson, "The Effects of Weldability of JBK-75 with Various Filler Metal Wire Additions", to be submitted to Welding Journal (1991).

5. S.H. Wang, D.K. Matlock, and D.I. Olson, "Physical Simulation for the High Temperature Creep Behavior of Weld Metal" to be submitted to the 3rd International Conference on Trends in Welding Research.

\subsection{Awards}

1. Charles H. Jennings Award from AWS for 1991. Award was made to M. Lisin, I.D. Choi, D.K. Matlock, and D.I. Olson for paper entitled "A Composite Modeling Analysis of Impression Creep Testing on Heterogeneous Materials". The paper was a product of this DOE-BES research program. 


\subsection{ANTICIPATED RESULTS DURING THE NEXT CONTRACT PERIOD}

\subsection{Current and Future Work}

1. Evaluate stainless steel metal matrix composite weld deposits for improved high temperature creep resistance. This work will extend the effort to date which has demonstrated the ability to make MMC weld deposits.

2. A mechanistic understanding of the ductile crack propagation through cored materials will be achieved.

3. Thorough characterization of fatigue crack propagation through cored material will be completed. The deformation mechanism which promotes fatigue cracks to follow regions of large microcompositional gradients will be identified.

4. The high temperature creep study of laminate composites with dynamic composition gradients will be completed. The results will include experimental creep data, an analytical model based on FEM methods, and an analysis of the local composition gradients and fine structure which develop during creep. 


\subsection{RESEARCH PERSONNEL}

David L. O1son - Co-Principal Investigatcr

David K. Matlock - Co-Principal Investigator

A. Wahid - Ph.D. Graduate Student (June 1992)

S.H. Wang - Ph.D. Graduate Student (August, 1992)

E. Kivineva - M.S. Graduate Student (Completed September 1991)

Clay Taylor - M.S. Graduate Student (Completed May 1991) 

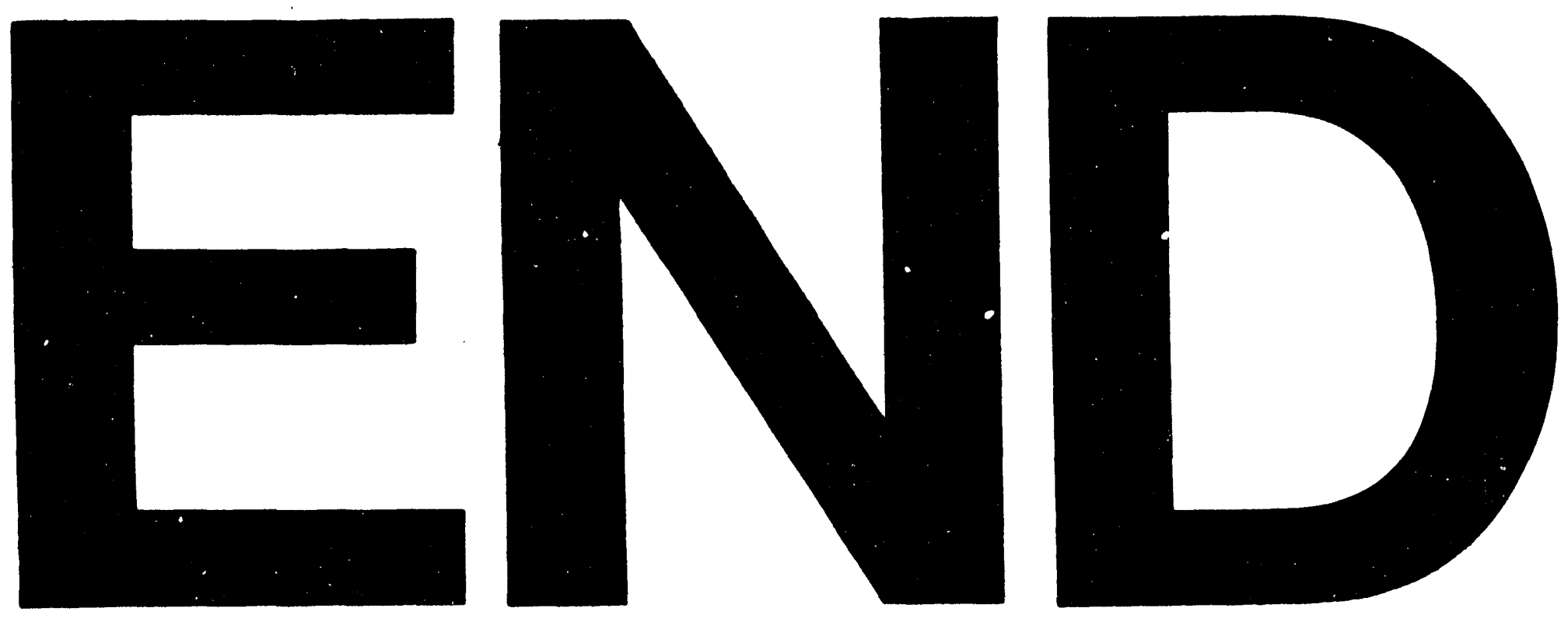

1

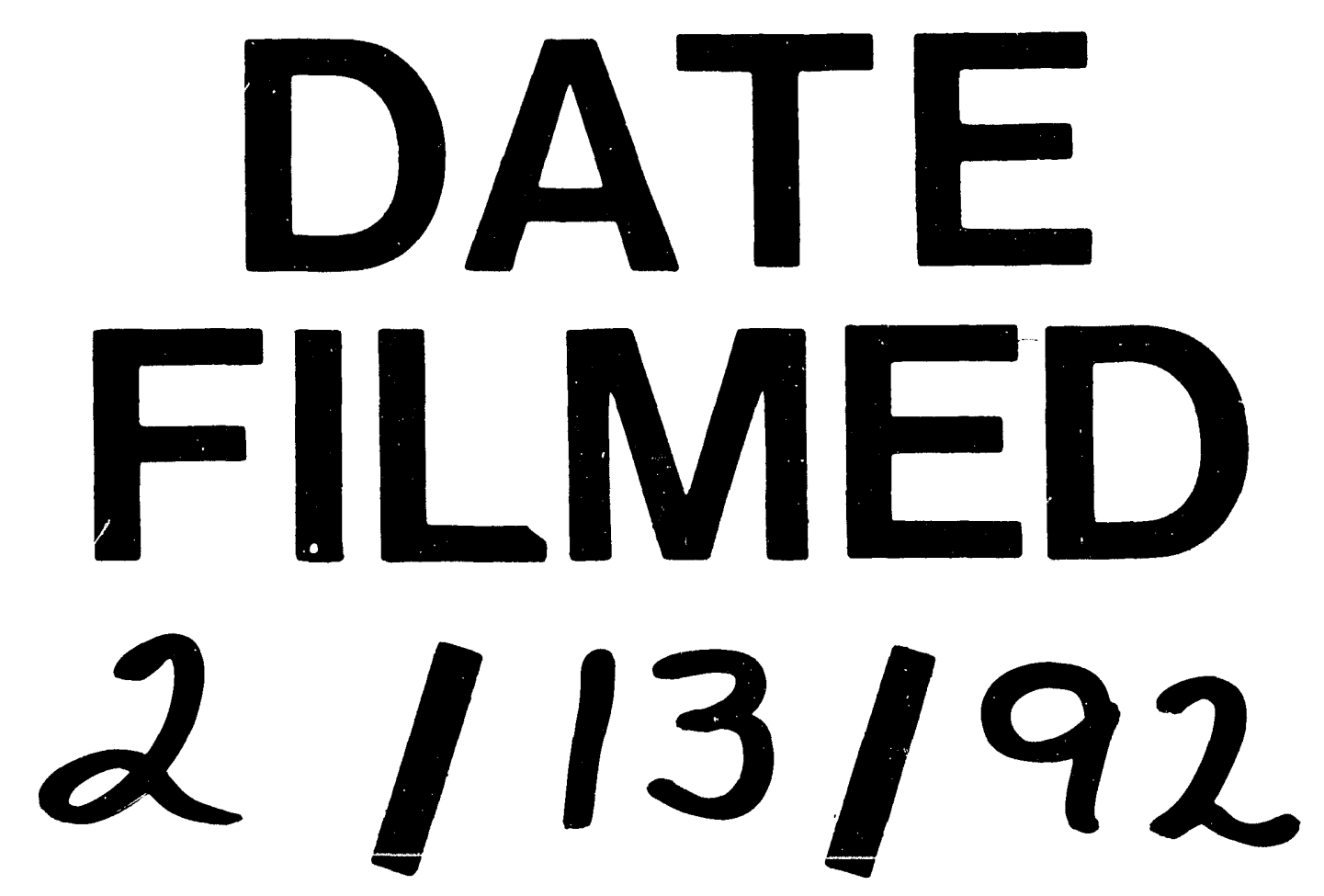


